\title{
A Novel Multiple Attribute Satisfaction Evaluation Approach with Hesitant Intuitionistic Linguistic Fuzzy Information
}

\author{
Shanghong Yang, ${ }^{1,2}$ Zhuo Sun, ${ }^{1}$ Yanbing Ju, and Chengya Qiao' \\ ${ }^{1}$ Research Institute of Bright Dairy, State Key Laboratory of Dairy Biotechnology, \\ Synergetic Innovation Center of Food Safety and Nutrition, Shanghai Engineering Research Center of Dairy Biotechnology, \\ Bright Dairy \& Food Co., Ltd., Shanghai 200436, China \\ ${ }^{2}$ School of Management and Economics, Beijing Institute of Technology, Beijing 100081, China
}

Correspondence should be addressed to Shanghong Yang; shanghong86@126.com

Received 21 April 2014; Revised 30 June 2014; Accepted 30 June 2014; Published 20 July 2014

Academic Editor: Pandian Vasant

Copyright (C) 2014 Shanghong Yang et al. This is an open access article distributed under the Creative Commons Attribution License, which permits unrestricted use, distribution, and reproduction in any medium, provided the original work is properly cited.

\begin{abstract}
This paper investigates the multiple attribute decision making (MADM) problems in which the attribute values take the form of hesitant intuitionistic linguistic fuzzy element (HILFE). Firstly, motivated by the idea of intuitionistic linguistic variables (ILVs) and hesitant fuzzy elements (HFEs), the concept, operational laws, and comparison laws of HILFE are defined. Then, some aggregation operators are developed for aggregating the hesitant intuitionistic linguistic fuzzy information, such as hesitant intuitionistic linguistic fuzzy weighted aggregation operators, hesitant intuitionistic linguistic fuzzy ordered weighted aggregation operators, and generalized hesitant intuitionistic linguistic fuzzy weighted aggregation operators. Moreover, some desirable properties of these operators and the relationships between them are discussed. Based on the hesitant intuitionistic linguistic fuzzy weighted average (HILFWA) operator and the hesitant intuitionistic linguistic fuzzy weighted geometric (HILFWG) operator, an approach for evaluating satisfaction degree is proposed under hesitant intuitionistic linguistic fuzzy environment. Finally, a practical example of satisfaction evaluation for milk products is given to illustrate the application of the proposed method and to demonstrate its practicality and effectiveness.
\end{abstract}

\section{Introduction}

Multiattribute decision making (MADM), which addresses the problem of making an optimal choice that has the highest degree of satisfaction from a set of feasible alternatives that are characterized in terms of their attributes, both quantitative and qualitative, is a usual task in human activities. Due to the inherent vagueness of human preferences as well as the objects being fuzzy and uncertain or data about the decisionmaking problems domain, the attributes involved in the decision problems are not always expressed as crisp numbers, and some of them are more suitable to be denoted by fuzzy numbers [1-6]. The fuzzy set theory originally proposed by Zadeh [7] is a very useful tool to describe uncertain information. However, in some real decision-making situations, the fuzzy set is imprecise resulting from characterizing the fuzziness just by a membership degree. On the basis of the fuzzy set theory, Atanassov [8,9] proposed the intuitionistic fuzzy set characterized by a membership function and a nonmembership function. Obviously, the intuitionistic fuzzy set can describe and characterize the fuzzy essence of the objective world more exquisitely, and it has received more and more attention since its appearance [10-20].

However, in the real world, decision makers usually cannot completely express their opinions by quantitative numbers, and some of them are more appropriately described by qualitative linguistic terms. Since linguistic variables [21] have been proposed, so far, a number of linguistic approaches have been defined such as 2-tuple linguistic [22], interval-valued 2-tuple linguistic [23], uncertain linguistic [24], trapezoid fuzzy linguistic [25], and trapezoid fuzzy 2-tuple linguistic [26] approaches. In order to express the uncertainty and ambiguity as accurate as possible, Wang and $\mathrm{Li}$ [27] proposed the concept of intuitionistic linguistic 
set based on linguistic variables and intuitionistic fuzzy set, which can overcome the defects for intuitionistic fuzzy set, which can only roughly represent criteria's membership and nonmembership to a particular concept, such as "good" and "bad," and for linguistic variables which usually implies that membership degree is 1 , and the nonmembership degree and hesitation degree of decision makers cannot be expressed.

In real decision-making process, we often encounter such situation that the decision makers are hesitant among a set of possible values which makes the outcome of decision making inconsistent. To solve this problem, the hesitant fuzzy set (HFS), an extension of fuzzy set [7], was proposed by Torra and Narukawa [28] and Torra [29], which permits the membership degree of an element to a given set to be represented by several possible numerical values. To accommodate more complex environment, several extensions of HFS have been presented, such as interval-valued hesitant fuzzy set (IVHFS) [30, 31], hesitant triangular fuzzy set (HTFS) [32], hesitant multiplicative set (HMS) [33], hesitant fuzzy linguistic term set (HFLTS) [34], and hesitant fuzzy uncertain linguistic set (HFULS) [35]. In particular, considering that the human judgments including preference information may be stated by a linguistic variable or an uncertain linguistic variable which permits the membership having a set of possible crisp values, Lin et al. [36] proposed the concepts of hesitant fuzzy linguistic set (HFLS) and hesitant fuzzy uncertain linguistic set (HFULS). Furthermore, Liu et al. [37] developed the hesitant intuitionistic fuzzy linguistic set (HIFLS) and the hesitant intuitionistic fuzzy uncertain linguistic set (HIFULS) which permit the possible membership degree and nonmembership degree of an element to a linguistic term and an uncertain linguistic term having sets of intuitionistic fuzzy numbers.

To the best of our knowledge, the existing methods under hesitant fuzzy environment are not suitable for dealing with MADM problems under hesitant intuitionistic linguistic fuzzy environment. In fact, when decision makers give their assessments on attributes which are in the form of intuitionistic linguistic variables (ILVs), they may also be hesitant among several possible ILVs. Therefore, inspired by the idea of the HFS, based on the ILVs, we propose a new fuzzy variable called hesitant intuitionistic linguistic fuzzy element (HILFE) which is composed of a set of ILVs. The main advantage of the HILFE is that it can describe the uncertain information by several linguistic variables in qualitative and intuitionistic fuzzy numbers adopted to demonstrate how much degree that an attribute value belongs and does not belong to a linguistic term in quantitative. For example, for a predefined linguistic set $S=\left\{s_{0}=\right.$ extremely low, $s_{1}=$ very low, $s_{2}=$ low, $s_{3}=$ medium, $s_{4}=$ high, $s_{5}=$ very high, $s_{6}=$ extremely high $\}$, when we can evaluate the "growth" of a company, we can utilize a HILFE $\left\{\left\langle s_{3},(0.6,0.3)\right\rangle,\left\langle s_{4},(0.6,0.2)\right\rangle,\left\langle s_{5},(0.5,0.4)\right\rangle\right\}$. Obviously, $s_{3}$, $s_{4}$, and $s_{5}$ indicate that the "growth" of a company may be "medium", "high," and "very high", and the intuitionistic fuzzy numbers " $(0.6,0.3)$," " $(0.6,0.2)$," and " $(0.5,0.4)$ " explain the degree that the "growth" of a company belongs to and does not belong to $s_{3}, s_{4}$, and $s_{5}$, respectively.

The remainder of this paper is organized as follows: some basic definitions of intuitionistic linguistic set and hesitant fuzzy set are briefly reviewed in Section 2. In Section 3, the concept, operational laws, score function, and accuracy function of the hesitant intuitionistic linguistic fuzzy element are defined. In Section 4, some hesitant intuitionistic linguistic fuzzy aggregation operators are proposed, and then some desirable properties of the proposed operators are investigated. In Section 5, we develop an approach to evaluate satisfaction degree with hesitant intuitionistic linguistic fuzzy information based on the proposed operators. In Section 6, a numerical example is given to illustrate the application of the proposed method. The paper is concluded in Section 7.

\section{Preliminaries}

To facilitate the following discussion, some basic definitions related to intuitionistic linguistic set and hesitant fuzzy set are briefly reviewed in this section.

Let $S=\left\{s_{0}, s_{1}, \ldots, s_{g}\right\}$ be a finite linguistic term set with odd cardinality, where $s_{i}$ represents a possible value for a linguistic term and $g+1$ is the cardinality of $S$. For example, when $g=6$, a set of seven terms $S$ can be given as follows.

$S=\left\{s_{0}=\right.$ extremely low, $s_{1}=$ very low, $s_{2}=$ low, $s_{3}=$ medium, $s_{4}=$ high, $s_{5}=$ very high, $s_{6}=$ extremely high $\}$.

In general, for any linguistic term set $S$, it is required that $s_{i}$ and $s_{j}$ must satisfy the following properties $[38,39]$.

(1) The set is ordered: $s_{i}>s_{j}$, if and only if $i>j$;

(2) there is the negation operator: $\operatorname{Neg}\left(s_{i}\right)=s_{j}$, such that $j=g-i$;

(3) maximum operator is $\max \left\{s_{i}, s_{j}\right\}=s_{i}$, if $i \geq j$;

(4) minimum operator is $\min \left\{s_{i}, s_{j}\right\}=s_{j}$, if $i \geq j$.

\subsection{Intuitionistic Linguistic Set}

Definition 1 (see [27]). Let $\bar{S}=\left\{s_{i} \mid s_{0} \leq s_{i} \leq s_{g}, i \in[0, g]\right\}$ be the continuous form of $S$ and let $X$ be in a given domain; an intuitionistic linguistic set $A$ in $X$ can be defined as

$$
A=\left\{\left\langle x,\left[s_{\theta(x)},\left(u_{A}(x), v_{A}(x)\right)\right]\right\rangle \mid x \in X\right\},
$$

where $s_{\theta(x)} \in \bar{S}, u_{A}(x) \in[0,1], v_{A}(x) \in[0,1]$, and $0 \leq$ $u_{A}(x)+v_{A}(x) \leq 1 . u_{A}(x)$ and $v_{A}(x)$ represent the membership degree and the nonmembership degree of the element $x$ to the linguistic variable $s_{\theta(x)}$, respectively. Let $\pi(x)=1-u_{A}(x)-$ $v_{A}(x), \pi(x) \in[0,1], \forall x \in X$; then, $\pi(x)$ is called a hesitancy degree of $x$ to the linguistic variable $s_{\theta(x)}$.

In $(1),\left\langle s_{\theta(x)},\left(u_{A}(x), v_{A}(x)\right)\right\rangle$ is an intuitionistic linguistic variable (ILV). For convenience, $a=\left\langle s_{\theta(a)},(u(a), v(a))\right\rangle$ is used to represent an ILV.

Definition 2 (see [27]). Let $a_{1}=\left\langle s_{\theta\left(a_{1}\right)},\left(u\left(a_{1}\right), v\left(a_{1}\right)\right)\right\rangle$ and $a_{2}=\left\langle s_{\theta\left(a_{2}\right)},\left(u\left(a_{2}\right), v\left(a_{2}\right)\right)\right\rangle$ be two ILVs and $\lambda \geq 0$; then, the operational laws of ILVs are defined as follows:

(1) $a_{1} \oplus a_{2}=\left\langle s_{\theta\left(a_{1}\right)+\theta\left(a_{2}\right)},\left(u\left(a_{1}\right)+u\left(a_{2}\right)-u\left(a_{1}\right) u\left(a_{2}\right)\right.\right.$, $\left.\left.v\left(a_{1}\right) v\left(a_{2}\right)\right)\right\rangle$;

(2) $a_{1} \otimes a_{2}=\left\langle s_{\theta\left(a_{1}\right) \times \theta\left(a_{2}\right)},\left(u\left(a_{1}\right) u\left(a_{2}\right), v\left(a_{1}\right)+v\left(a_{j}\right)-\right.\right.$ $\left.\left.v\left(a_{1}\right) v\left(a_{2}\right)\right)\right\rangle$; 
(3) $\lambda a_{1}=\left\langle s_{\lambda \times \theta\left(a_{1}\right)},\left(1-\left(1-u\left(a_{1}\right)\right)^{\lambda},\left(v\left(a_{1}\right)\right)^{\lambda}\right)\right\rangle$;

(4) $a_{1}^{\lambda}=\left\langle s_{\theta\left(a_{1}\right)^{\lambda}},\left(\left(u\left(a_{1}\right)\right)^{\lambda}, 1-\left(1-v\left(a_{1}\right)\right)^{\lambda}\right)\right\rangle$.

Definition 3 (see [40]). Let $a_{1}=\left\langle s_{\theta\left(a_{1}\right)},\left(u\left(a_{1}\right), v\left(a_{1}\right)\right)\right\rangle$ be an ILV; the score function $S\left(a_{1}\right)$ and the accuracy function $H\left(a_{1}\right)$ of $a_{1}$ are defined, respectively, as follows:

$$
\begin{gathered}
S\left(a_{1}\right)=\frac{1}{2} \times\left(u\left(a_{1}\right)+1-v\left(a_{1}\right)\right) \times \frac{\theta\left(a_{1}\right)}{g}, \\
H\left(a_{1}\right)=\left(u\left(a_{1}\right)+v\left(a_{1}\right)\right) \times \frac{\theta\left(a_{1}\right)}{g} .
\end{gathered}
$$

Theorem 4 (see [40]). Let $a_{1}=\left\langle s_{\theta\left(a_{1}\right)},\left(u\left(a_{1}\right), v\left(a_{1}\right)\right)\right\rangle$ and $a_{2}=$ $\left\langle s_{\theta\left(a_{2}\right)},\left(u\left(a_{2}\right), v\left(a_{2}\right)\right)\right\rangle$ be two ILVs; then, they can be compared by the following laws:

(1) if $S\left(a_{1}\right)>S\left(a_{2}\right)$, then $a_{1}>a_{2}$;

(2) if $S\left(a_{1}\right)=S\left(a_{2}\right)$, then

$$
\begin{aligned}
& \text { if } H\left(a_{1}\right)>H\left(a_{2}\right), \text { then } a_{1}>a_{2} \text {; } \\
& \text { if } H\left(a_{1}\right)=H\left(a_{2}\right), \text { then } a_{1}=a_{2} .
\end{aligned}
$$

\subsection{Hesitant Fuzzy Set}

Definition 5 (see [29]). Let $X$ be a fixed set; then, a hesitant fuzzy set (HFS) on $X$ is in terms of a function that when applied to $X$ returns a subset of $[0,1]$, which can be represented by the following mathematical symbol:

$$
E=\{\langle x, \tilde{h}(x)\rangle \mid x \in X\}
$$

where $\tilde{h}(x)=\bigcup_{\tilde{r}(x) \in \tilde{h}(x)}\{\widetilde{r}(x)\}$ is a set of some values in $[0,1]$, denoting the possible membership degrees of the element $x \in$ $X$ to the set $E$. For convenience, Liu et al. [37] called $\tilde{h}(x)$ a hesitant fuzzy element (HFE) and $E$ the set of all HFEs.

Definition 6 (see [41]). Let $\tilde{h}=\bigcup_{\tilde{r} \in \tilde{h}}\{\tilde{r}\}, \widetilde{h}_{1}=\bigcup_{\widetilde{r}_{1} \in \tilde{h}_{1}}\left\{\widetilde{r}_{1}\right\}$, and $\tilde{h}_{2}=\bigcup_{\widetilde{r}_{2} \in \widetilde{h}_{2}}\left\{\tilde{r}_{2}\right\}$ be any three HFEs, and $\beta \geq 0$; then, some operational laws of HFEs are defined as follows:
(1) $\tilde{h}^{\beta}=\bigcup_{\tilde{r} \in \tilde{h}}\left\{\widetilde{r}^{\beta}\right\}$;
(2) $\beta \tilde{h}=\bigcup_{\tilde{r} \in \tilde{h}}\left\{1-(1-\tilde{r})^{\beta}\right\}$;

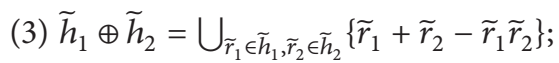
(4) $\tilde{h}_{1} \otimes \tilde{h}_{2}=\bigcup_{\widetilde{r}_{1} \in \tilde{h}_{1}, \tilde{r}_{2} \in \tilde{h}_{2}}\left\{\widetilde{r}_{1} \widetilde{r}_{2}\right\}$.

Definition 7 (see [37]). For two HFEs $\widetilde{h}_{1}=\bigcup_{\widetilde{r}_{1} \in \tilde{h}_{1}}\left\{\widetilde{r}_{1}\right\}$ and $\widetilde{h}_{2}=\bigcup_{\widetilde{r}_{2} \in \widetilde{h}_{2}}\left\{\widetilde{r}_{2}\right\}$, let $S\left(\widetilde{h}_{i}\right)=\left(1 / \# \widetilde{h}_{i}\right) \sum_{\widetilde{r}_{i} \in \widetilde{h}_{i}} \widetilde{r}_{i}$ and $V\left(\widetilde{h}_{i}\right)$ $=\sqrt{\left(1 / \# \widetilde{h}_{i}\right) \sum_{\tilde{r}_{i} \in \tilde{h}_{i}}\left(\widetilde{r}_{i}-S\left(\widetilde{h}_{i}\right)\right)^{2}}$ be the score function and variance function of $\widetilde{h}_{i}(i=1,2)$, respectively, where $\# \widetilde{h}_{i}$ is the number of elements in $\widetilde{h}_{i}(i=1,2)$; then,

(1) if $S\left(\widetilde{h}_{1}\right)>S\left(\widetilde{h}_{2}\right)$, then $\widetilde{h}_{1}$ is superior to $\widetilde{h}_{2}$, denoted by $\tilde{h}_{1}>\widetilde{h}_{2}$;
(2) if $S\left(\tilde{h}_{1}\right)=S\left(\tilde{h}_{2}\right)$, then

(a) if $V\left(\widetilde{h}_{1}\right)>V\left(\widetilde{h}_{2}\right)$, then $\tilde{h}_{1}$ is inferior to $\tilde{h}_{2}$, denoted by $\tilde{h}_{1} \prec \tilde{h}_{2}$;

(b) if $V\left(\widetilde{h}_{1}\right)=V\left(\widetilde{h}_{2}\right)$, then $\widetilde{h}_{1}$ is equivalent to $\widetilde{h}_{2}$, denoted by $\widetilde{h}_{1}=\widetilde{h}_{2}$.

\section{Hesitant Intuitionistic Linguistic Fuzzy Set}

Based on the intuitionistic linguistic set and the hesitant fuzzy set, we propose the definition of the hesitant intuitionistic linguistic fuzzy set, as well as the operational laws, score function, and accuracy function in what follows.

Definition 8 . Let $X$ be a nonempty set of the universe and $\bar{S}$ a continuous linguistic term set of $S=\left\{s_{0}, s_{1}, \ldots, s_{g}\right\}$; then, a hesitant intuitionistic linguistic fuzzy set (HILFS) on $X$ can be expressed by the mathematical symbol as follows:

$$
H=\{\langle x, h(x)\rangle \mid x \in X\}
$$

where $h(x)=\bigcup_{r(x) \in h(x)}\{r(x)\}$ is a set of ILVs; that is, $r(x)$ $=\left\langle s_{\theta(x)},(\mu(x), v(x))\right\rangle$, denoting the possible membership degrees of the element $x \in X$ to the set $H$. For convenience, one calls $h=\bigcup_{r \in h}\{r\}$ a hesitant intuitionistic linguistic fuzzy element (HILFE) and $H$ the set of all HILFEs.

Definition 9. Let $h, h_{1}$, and $h_{2}$ be any three HILFEs, and $\beta \geq 0$; then, the operational laws of HILFEs are defined as follows:
(1) $h_{1} \oplus h_{2}=\bigcup_{r_{1} \in h_{1}, r_{2} \in h_{2}}\left\{\left\langle s_{\theta\left(r_{1}\right)+\theta\left(r_{2}\right)},\left(\mu\left(r_{1}\right)+\mu\left(r_{2}\right)-\right.\right.\right.$ $\left.\left.\left.\mu\left(r_{1}\right) \mu\left(r_{2}\right), v\left(r_{1}\right) v\left(r_{2}\right)\right)\right\rangle\right\}$
(2) $h_{1} \otimes h_{2}=\bigcup_{r_{1} \in h_{1}, r_{2} \in h_{2}}\left\{\left\langle s_{\theta\left(r_{1}\right) \times \theta\left(r_{2}\right)},\left(\mu\left(r_{1}\right) \mu\left(r_{2}\right), v\left(r_{1}\right)+\right.\right.\right.$ $\left.\left.\left.v\left(r_{2}\right)-v\left(r_{1}\right) v\left(r_{2}\right)\right)\right\rangle\right\}$
(3) $\beta h=\bigcup_{r \in h}\left\{\left\langle s_{\beta \times \theta(r)},\left(1-(1-\mu(r))^{\beta}, v(r)^{\beta}\right)\right\rangle\right\}$;
(4) $h^{\beta}=\bigcup_{r \in h}\left\{\left\langle s_{\theta(r)^{\beta}},\left(\mu(r)^{\beta}, 1-(1-v(r))^{\beta}\right)\right\rangle\right\}$.

Obviously, the above operational results are still HIFLEs.

Theorem 10. Let $h_{1}$ and $h_{2}$ be two HILFEs, and $\lambda \geq 0$; the calculation rules are shown as follows:
(1) $h_{1} \oplus h_{2}=h_{2} \oplus h_{1}$;
(2) $h_{1} \otimes h_{2}=h_{2} \otimes h_{1}$
(3) $\lambda h_{1} \oplus \lambda h_{2}=\lambda\left(h_{1} \oplus h_{2}\right)$;
(4) $h_{1}^{\lambda} \otimes h_{2}^{\lambda}=\left(h_{1} \otimes h_{2}\right)^{\lambda}$.

Definition 11. Let $h$ be a HILFE; then, the score function $S(h)$ of $h$ can be represented as follows:

$$
S(h)=\frac{1}{\# h} \sum_{r \in h} \frac{\theta(h)(1+\mu(h)-v(h))}{2 g},
$$

where $\# h$ is the number of ILVs in $h$ and $g+1$ is the cardinality of linguistic term set $S$. 
Definition 12. Let $h$ be a HILFE; then, the accuracy function $P(h)$ of $h$ can be represented as follows:

$$
P(h)=\frac{1}{\# h} \sum_{r \in h} \frac{\theta(h)(\mu(h)+v(h))}{g},
$$

where $\# h$ is the number of ILVs in $h$ and $g+1$ is the cardinality of linguistic term set $S$.

Theorem 13. Let $h_{1}$ and $h_{2}$ be two HILFEs and let $S\left(h_{i}\right)$ and $P\left(h_{i}\right)$ be the score value and accuracy degree of $h_{i}(i=$ $1,2)$, respectively; then, one has the following.

(1) If $S\left(h_{1}\right)<S\left(h_{2}\right)$, then $h_{1}$ is smaller than $h_{2}$, denoted by $h_{1}<h_{2}$.

(2) If $S\left(h_{1}\right)=S\left(h_{2}\right)$, then one has the following:

(a) if $P\left(h_{1}\right)=P\left(h_{2}\right)$, then $h_{1}$ is equal to $h_{2}$, denoted by $h_{1}=h_{2}$

(b) if $P\left(h_{1}\right)<P\left(h_{2}\right)$, then $h_{1}$ is smaller than $h_{2}$, denoted by $h_{1}<h_{2}$.

\section{Hesitant Intuitionistic Linguistic Fuzzy Aggregation Operators}

Motivated by the operational laws of HILFEs, in the following, some aggregation operators are developed for aggregating the hesitant intuitionistic linguistic fuzzy information.

\subsection{Hesitant Intuitionistic Linguistic Fuzzy Weighted}

\section{Aggregation Operators}

Definition 14. Let $h_{i}(i=1,2, \ldots, n)$ be a collection of HILFEs and let $w=\left(w_{1}, w_{2}, \ldots, w_{n}\right)^{T}$ be the weight vector of them, with $w_{i} \in[0,1], i=1,2, \ldots, n$, and $\sum_{i=1}^{n} w_{i}=1$; then, the hesitant intuitionistic linguistic fuzzy weighted average (HILFWA) operator is a mapping HILFWA: $H^{n} \rightarrow H$, and

$$
\operatorname{HILFWA}\left(h_{1}, h_{2}, \ldots, h_{n}\right)=\underset{i=1}{\stackrel{n}{\oplus}} w_{i} h_{i},
$$

where $H$ is a hesitant intuitionistic linguistic fuzzy set.

Theorem 15. Let $h_{i}(i=1,2, \ldots, n)$ be a collection of HILFEs, and let $w=\left(w_{1}, w_{2}, \ldots, w_{n}\right)^{T}$ be the weight vector of them, with $w_{i} \in[0,1], i=1,2, \ldots, n$, and $\sum_{i=1}^{n} w_{i}=1$; then; their aggregated value by the HILFWA operator is still a HILFE, and

$$
\begin{aligned}
= & \operatorname{HILFWA}\left(h_{1}, h_{2}, \ldots, h_{n}\right) \\
& \bigcup_{r_{1} \in h_{1}, r_{2} \in h_{2}, \ldots, r_{n} \in h_{n}}\left\{\left\langles_{\sum_{i=1}^{n} w_{i} \cdot \theta\left(r_{i}\right)},\right.\right. \\
& \left(1-\prod_{i=1}^{n}\left(1-\mu\left(r_{i}\right)\right)^{w_{i}},\right. \\
& \left.\left.\left.\prod_{i=1}^{n} v\left(r_{i}\right)^{w_{i}}\right)\right\rangle\right\} .
\end{aligned}
$$

In particular, if $w=(1 / n, 1 / n, \ldots, 1 / n)^{T}$, then the HILFWA operator reduces to the hesitant intuitionistic linguistic fuzzy average (HILFA) operator:

$$
\begin{aligned}
& \operatorname{HILFA}\left(h_{1}, h_{2}, \ldots, h_{n}\right) \\
& =\bigoplus_{i=1}^{n} \frac{1}{n} h_{i} \\
& =\bigcup_{r_{1} \in h_{1}, r_{2} \in h_{2}, \ldots, r_{n} \in h_{n}}\left\{\left\langles_{\sum_{i=1}^{n}(1 / n) \cdot \theta\left(r_{i}\right)},\right.\right. \\
& \left(1-\prod_{i=1}^{n}\left(1-\mu\left(r_{i}\right)\right)^{1 / n},\right. \\
& \left.\left.\left.\prod_{i=1}^{n} v\left(r_{i}\right)^{1 / n}\right)\right\rangle\right\} .
\end{aligned}
$$

Some desirable properties of the HILFWA operator are given as follows.

Theorem 16 (idempotency). If all HILFEs $h_{i}(i=1,2, \ldots, n)$ are equal and $h_{i}=\left\{\left\langle s_{\theta},(\mu, v)\right\rangle\right\}$ for all $i=1,2, \ldots, n$, then

$$
\operatorname{HILFWA}\left(h_{1}, h_{2}, \ldots, h_{n}\right)=\left\{\left\langle s_{\theta},(\mu, v)\right\rangle\right\} .
$$

Proof. Since $h_{i}=\left\{\left\langle s_{\theta},(\mu, v)\right\rangle\right\}$ for all $i=1,2, \ldots, n$, then

$$
\begin{aligned}
& \operatorname{HILFWA}\left(h_{1}, h_{2}, \ldots, h_{n}\right) \\
&=\bigcup_{r_{i} \in h_{i}}\left\{\left\langles_{\sum_{i=1}^{n} w_{i} \cdot \theta\left(r_{i}\right)},\right.\right. \\
& \\
&\left(1-\prod_{i=1}^{n}\left(1-\mu\left(r_{i}\right)\right)^{w_{i}},\right. \\
&\left.\left.\left.\prod_{i=1}^{n} v\left(r_{i}\right)^{w_{i}}\right)\right\rangle\right\}
\end{aligned}
$$

$$
\begin{aligned}
&=\bigcup_{r \in h}\left\{\left\langles_{\sum_{i=1}^{n} w_{i} \cdot \theta},\right.\right. \\
&\left(1-\prod_{i=1}^{n}(1-\mu)^{w_{i}},\right. \\
&\left.\left.\left.\prod_{i=1}^{n} v^{w_{i}}\right)\right\rangle\right\}=\left\{\left\langle s_{\theta},(\mu, v)\right\rangle\right\} .
\end{aligned}
$$

Theorem 17 (boundedness). Let $h_{i}(i=1,2, \ldots, n)$ be a collection of HILFEs; if $s_{\theta^{-}}=\min _{1 \leq i \leq n}\left\{s_{\theta\left(r_{i}\right)} \mid r_{i} \in h_{i}\right\}, s_{\theta^{+}}=$ $\max _{1 \leq i \leq n}\left\{s_{\theta\left(r_{i}\right)} \mid r_{i} \in h_{i}\right\}, \mu^{-}=\min _{1 \leq i \leq n}\left\{\mu\left(r_{i}\right) \mid r_{i} \in h_{i}\right\}$, 
$\mu^{+}=\max _{1 \leq i \leq n}\left\{\mu\left(r_{i}\right) \mid r_{i} \in h_{i}\right\}, v^{-}=\min _{1 \leq i \leq n}\left\{v\left(r_{i}\right) \mid r_{i} \in h_{i}\right\}$, and $v^{+}=\max _{1 \leq i \leq n}\left\{v\left(r_{i}\right) \mid r_{i} \in h_{i}\right\}$, then

$$
\begin{aligned}
\left\langle s_{\theta^{-}},\left(\mu^{-}, v^{+}\right)\right\rangle & \leq \operatorname{HILFWA}\left(h_{1}, h_{2}, \ldots, h_{n}\right) \\
& \leq\left\langle s_{\theta^{+}},\left(\mu^{+}, v^{-}\right)\right\rangle .
\end{aligned}
$$

Proof. Since $s_{\theta^{-}}=\min _{1 \leq i \leq n}\left\{s_{\theta\left(r_{i}\right)} \mid r_{i} \in h_{i}\right\}, s_{\theta^{+}}=$ $\max _{1 \leq i \leq n}\left\{s_{\theta\left(r_{i}\right)} \mid r_{i} \in h_{i}\right\}, \mu^{-}=\min _{1 \leq i \leq n}\left\{\mu\left(r_{i}\right) \mid r_{i} \in h_{i}\right\}$, $\mu^{+}=\max _{1 \leq i \leq n}\left\{\mu\left(r_{i}\right) \mid r_{i} \in h_{i}\right\}, v^{-}=\min _{1 \leq i \leq n}\left\{v\left(r_{i}\right) \mid r_{i} \in h_{i}\right\}$, and $v^{+}=\max _{1 \leq i \leq n}\left\{v\left(r_{i}\right) \mid r_{i} \in h_{i}\right\}$, we have

$$
\begin{gathered}
\theta^{-} \leq \theta\left(r_{i}\right) \leq \theta^{+}, \quad \mu^{-} \leq \mu\left(r_{i}\right) \leq \mu^{+}, \\
v^{-} \leq v\left(r_{i}\right) \leq v^{+}, \\
\forall i=1,2, \ldots, n .
\end{gathered}
$$

Then,

$$
\begin{gathered}
\sum_{i=1}^{n} w_{i} \theta\left(r_{i}\right) \geq \sum_{i=1}^{n} w_{i} \theta^{-}=\theta^{-}, \\
1-\prod_{i=1}^{n}\left(1-\mu\left(r_{i}\right)\right)^{w_{i}} \geq 1-\prod_{i=1}^{n}\left(1-\mu^{-}\right)^{w_{i}}=\mu^{-}, \\
\prod_{i=1}^{n} v\left(r_{i}\right)^{w_{i}} \leq \prod_{i=1}^{n}\left(v^{+}\right)^{w_{i}}=v^{+} .
\end{gathered}
$$

That is,

$$
\begin{gathered}
\frac{1}{\# h} \sum_{r \in h}\left(( \sum _ { i = 1 } ^ { n } w _ { i } \cdot \theta ( r _ { i } ) ) \left(1+1-\prod_{i=1}^{n}\left(1-\mu\left(r_{i}\right)\right)^{w_{i}}\right.\right. \\
\left.\left.-\prod_{i=1}^{n} v\left(r_{i}\right)^{w_{i}}\right)\right) \\
\times(2 g)^{-1} \geq \frac{\left(1+\mu^{-}-v^{+}\right) \times \theta^{-}}{2 g}
\end{gathered}
$$

where $\# h$ is the numbers of ILVs in $\operatorname{HILFWA}\left(h_{1}, h_{2}, \ldots, h_{n}\right)$ and $g+1$ is the cardinality of linguistic term set $S$. Therefore, according to Theorem 13, we obtain

$$
\operatorname{HILFWA}\left(h_{1}, h_{2}, \ldots, h_{n}\right) \geq\left\langle s_{\theta^{-}},\left(\mu^{-}, v^{+}\right)\right\rangle \text {. }
$$

Similarly,

$$
\operatorname{HILFWA}\left(h_{1}, h_{2}, \ldots, h_{n}\right) \leq\left\langle s_{\theta^{+}},\left(\mu^{+}, v^{-}\right)\right\rangle .
$$

Therefore,

$$
\left\langle s_{\theta^{-}},\left(\mu^{-}, v^{+}\right)\right\rangle \leq \operatorname{HILFWA}\left(h_{1}, h_{2}, \ldots, h_{n}\right) \leq\left\langle s_{\theta^{+}},\left(\mu^{+}, v^{-}\right)\right\rangle .
$$

Definition 18. Let $h_{i}(i=1,2, \ldots, n)$ be a collection of HILFEs and let $w=\left(w_{1}, w_{2}, \ldots, w_{n}\right)^{T}$ be the weight vector of them, with $w_{i} \in[0,1], i=1,2, \ldots, n$, and $\sum_{i=1}^{n} w_{i}=1$; then, the hesitant intuitionistic linguistic fuzzy weighted geometric (HILFWG) operator is a mapping HILFWG: $H^{n} \rightarrow H$, and

$$
\operatorname{HILFWG}\left(h_{1}, h_{2}, \ldots, h_{n}\right)=\stackrel{\otimes}{i=1}_{i}^{n}\left(h_{i}\right)^{w_{i}},
$$

where $H$ is a hesitant intuitionistic linguistic fuzzy set.

Theorem 19. Let $h_{i}(i=1,2, \ldots, n)$ be a collection of HILFEs and let $w=\left(w_{1}, w_{2}, \ldots, w_{n}\right)^{T}$ be the weight vector of them, with $w_{i} \in[0,1], i=1,2, \ldots, n$, and $\sum_{i=1}^{n} w_{i}=1$; then, their aggregated value by the HILFWG operator is still a HILFE, and

$$
\begin{aligned}
& \operatorname{HILFWG}\left(h_{1}, h_{2}, \ldots, h_{n}\right) \\
& =\bigcup_{r_{1} \in h_{1}, r_{2} \in h_{2}, \ldots, r_{n} \in h_{n}}\left\{\left\langles_{\prod_{i=1}^{n} \theta\left(r_{i}\right)^{w_{i}},}\right.\right. \\
& \qquad\left(\prod_{i=1}^{n} \mu\left(r_{i}\right)^{w_{i}},\right. \\
& \left.\left.\left.1-\prod_{i=1}^{n}\left(1-v\left(r_{i}\right)\right)^{w_{i}}\right)\right\rangle\right\} .
\end{aligned}
$$

In particular, if $w=(1 / n, 1 / n, \ldots, 1 / n)^{T}$, then the HILFWG operator reduces to the hesitant intuitionistic linguistic fuzzy geometric (HILFG) operator:

$$
\begin{aligned}
& \operatorname{HILFG}\left(h_{1}, h_{2}, \ldots, h_{n}\right) \\
&=\bigotimes_{i=1}^{n}\left(h_{i}\right)^{1 / n}\{ \\
&=r_{r_{1} \in h_{1}, r_{2} \in h_{2}, \ldots, r_{n} \in h_{n}}\{ s_{\prod_{i=1}^{n} \theta\left(r_{i}\right)^{1 / n},} \\
&\left(\prod_{i=1}^{n} \mu\left(r_{i}\right)^{1 / n},\right. \\
&\left.\left.\left.1-\prod_{i=1}^{n}\left(1-v\left(r_{i}\right)\right)^{1 / n}\right)\right\rangle\right\} .
\end{aligned}
$$

Similar to the HILFWA operator, the HILFWG operator also has the properties of idempotency and boundedness under some conditions, which can be proved similar to Theorems 16 and 17.

Lemma 20 (see [42]). Let $x_{j}>0, \lambda_{j}>0, j=1,2, \ldots, n$, and $\sum_{j=1}^{n} \lambda_{j}=1$; then,

$$
\prod_{j=1}^{n} x_{j}^{\lambda_{j}} \leq \sum_{j=1}^{n} \lambda_{j} x_{j}
$$

with equality if and only if $x_{1}=x_{2}=\cdots=x_{n}$.

Theorem 21. Let $h_{i}(i=1,2, \ldots, n)$ be a collection of HILFEs and let $w=\left(w_{1}, w_{2}, \ldots, w_{n}\right)^{T}$ be the weight vector of them, with $w_{i} \in[0,1], i=1,2, \ldots, n$, and $\sum_{i=1}^{n} w_{i}=1$, and let $n$ 
be the balancing coefficient which plays a role of balance; then, one has

$$
\operatorname{HILFWG}\left(h_{1}, h_{2}, \ldots, h_{n}\right) \leq \operatorname{HILFWA}\left(h_{1}, h_{2}, \ldots, h_{n}\right) .
$$

Proof. According to Lemma 20, for any $r_{i}=\left\langle s_{\theta\left(r_{i}\right)},\left(u\left(r_{i}\right)\right.\right.$, $\left.\left.v\left(r_{i}\right)\right)\right\rangle \in h_{i}, i=1,2, \ldots, n$, we have

$$
\begin{gathered}
\prod_{i=1}^{n} \theta\left(r_{i}\right)^{w_{i}} \leq \sum_{i=1}^{n} w_{i} \theta\left(r_{i}\right), \\
\prod_{i=1}^{n} \mu\left(r_{i}\right)^{w_{i}} \leq \sum_{i=1}^{n} w_{i} \mu\left(r_{i}\right) \\
=1-\sum_{i=1}^{n} w_{i}\left(1-\mu\left(r_{i}\right)\right) \leq 1-\prod_{i=1}^{n}\left(1-\mu\left(r_{i}\right)\right)^{w_{i}}, \\
1-\prod_{i=1}^{n}\left(1-v\left(r_{i}\right)\right)^{w_{i}} \\
\geq 1-\sum_{i=1}^{n} w_{i}\left(1-v\left(r_{i}\right)\right)=\sum_{i=1}^{n} w_{i} v\left(r_{i}\right) \geq \prod_{i=1}^{n} v\left(r_{i}\right)^{w_{i}} .
\end{gathered}
$$

That is,

$$
\begin{array}{r}
\frac{1}{\# h_{1} \sum_{r_{i} \in h_{i}}\left(\prod_{i=1}^{n} \theta\left(r_{i}\right)^{w_{i}} \times(1\right.}+\prod_{i=1}^{n} \mu\left(r_{i}\right)^{w_{i}} \\
\left.\left.-1-\prod_{i=1}^{n}\left(1-v\left(r_{i}\right)\right)^{w_{i}}\right)\right) \\
\times(2 g)^{-1} \\
\leq \frac{1}{\# h_{2}} \sum_{r_{i} \in h_{i}}\left(\sum_{i=1}^{n} w_{i} \theta\left(r_{i}\right) \times\left(1+1-\prod_{i=1}^{n}\left(1-\mu\left(r_{i}\right)\right)^{w_{i}}\right.\right. \\
\left.\left.-\prod_{i=1}^{n} v\left(r_{i}\right)^{w_{i}}\right)\right) \times(2 g)^{-1},
\end{array}
$$

where $\# h_{1}$ and $\# h_{2}$ are the numbers of ILVs in HILFWG $\left(h_{1}\right.$, $\left.h_{2}, \ldots, h_{n}\right)$ and HILFWA $\left(h_{1}, h_{2}, \ldots, h_{n}\right)$, respectively, and $g+$ 1 is the cardinality of linguistic term set $S$. Therefore, according to Theorem 13 , we obtain

$$
\operatorname{HILFWG}\left(h_{1}, h_{2}, \ldots, h_{n}\right) \leq \operatorname{HILFWA}\left(h_{1}, h_{2}, \ldots, h_{n}\right) \text {. }
$$

\subsection{Hesitant Intuitionistic Linguistic Fuzzy Ordered Weighted Aggregation Operators}

Definition 22. Let $h_{i}(i=1,2, \ldots, n)$ be a collection of HILFEs and let $\omega=\left(\omega_{1}, \omega_{2}, \ldots, \omega_{n}\right)^{T}$ be the aggregationassociated vector such that $\omega_{i} \in[0,1], i=1,2, \ldots, n$, and $\sum_{i=1}^{n} \omega_{i}=1$; then, the hesitant intuitionistic linguistic fuzzy ordered weighted average (HILFOWA) operator is a mapping HILFOWA: $H^{n} \rightarrow H$, and

$$
\operatorname{HILFOWA}\left(h_{1}, h_{2}, \ldots, h_{n}\right)=\stackrel{n}{\stackrel{n}{\oplus}} \omega_{i=1} h_{\sigma(i)},
$$

where $H$ is a hesitant intuitionistic linguistic fuzzy set. $h_{\sigma(i)}$ is the $i$ th largest element in $h_{i}(i=1,2, \ldots, n)$.

Theorem 23. Let $h_{i}(i=1,2, \ldots, n)$ be a collection of HILFEs and let $\omega=\left(\omega_{1}, \omega_{2}, \ldots, \omega_{n}\right)^{T}$ be the aggregation-associated vector such that $\omega_{i} \in[0,1], i=1,2, \ldots, n$, and $\sum_{i=1}^{n} \omega_{i}=1$; then, their aggregated value by the HILFOWA operator is still a HILFE, and

$$
\begin{aligned}
& \operatorname{HILFOWA}\left(h_{1}, h_{2}, \ldots, h_{n}\right) \\
& =\bigcup_{r_{\sigma(1)} \in h_{\sigma(1)}, r_{\sigma(2)} \in h_{\sigma(2)}, \ldots, r_{\sigma(n)} \in h_{\sigma(n)}}\left\{\left\langles_{\sum_{i=1}^{n} \omega_{i} \cdot \theta\left(r_{\sigma(i)}\right)},\right.\right. \\
& \left(1-\prod_{i=1}^{n}\left(1-\mu\left(r_{\sigma(i)}\right)\right)^{\omega_{i}},\right. \\
& \left.\left.\left.\prod_{i=1}^{n} v\left(r_{\sigma(i)}\right)^{\omega_{i}}\right)\right\rangle\right\} .
\end{aligned}
$$

Similar to the HILFWA operator, the HILFOWA operator also has the properties of idempotency and boundedness under some conditions, which can be proved similar to Theorems 16 and 17. Furthermore, the HILFOWA operator also has the property of commutativity.

Theorem 24 (commutativity). Let $h_{i}(i=1,2, \ldots, n)$ be a collection of HILFEs. If $\left\{h_{1}^{\prime}, h_{2}^{\prime}, \ldots, h_{n}^{\prime}\right\}$ is any permutation of $\left\{h_{1}, h_{2}, \ldots, h_{n}\right\}$, then

$$
\operatorname{HILFOWA}\left(h_{1}^{\prime}, h_{2}^{\prime}, \ldots, h_{n}^{\prime}\right)=\operatorname{HILFOWA}\left(h_{1}, h_{2}, \ldots, h_{n}\right) \text {. }
$$

Proof. Since $\left\{h_{1}^{\prime}, h_{2}^{\prime}, \ldots, h_{n}^{\prime}\right\}$ is a permutation of $\left\{h_{1}, h_{2}, \ldots\right.$, $\left.h_{n}\right\}$, we have $h_{\sigma(i)}^{\prime}=h_{\sigma(i)}$, for all $i=1,2, \ldots, n$. Then, based on Definition 22, we obtain

$$
\operatorname{HILFOWA}\left(h_{1}^{\prime}, h_{2}^{\prime}, \ldots, h_{n}^{\prime}\right)=\operatorname{HILFOWA}\left(h_{1}, h_{2}, \ldots, h_{n}\right) \text {. }
$$

Definition 25. Let $h_{i}(i=1,2, \ldots, n)$ be a collection of HILFEs and let $\omega=\left(\omega_{1}, \omega_{2}, \ldots, \omega_{n}\right)^{T}$ be the aggregationassociated vector such that $\omega_{i} \in[0,1], i=1,2, \ldots, n$, and $\sum_{i=1}^{n} \omega_{i}=1$; then, the hesitant intuitionistic linguistic fuzzy ordered weighted geometric (HILFOWG) operator is a mapping HILFOWG: $H^{n} \rightarrow H$, and

$$
\operatorname{HILFOWG}\left(h_{1}, h_{2}, \ldots, h_{n}\right)=\stackrel{n}{\otimes}\left(h_{\sigma(i)}\right)^{\omega_{i}},
$$

where $H$ is a hesitant intuitionistic linguistic fuzzy set. $h_{\sigma(i)}$ is the $i$ th largest element in $h_{i}(i=1,2, \ldots, n)$. 
Theorem 26. Let $h_{i}(i=1,2, \ldots, n)$ be a collection of HILFEs and let $\omega=\left(\omega_{1}, \omega_{2}, \ldots, \omega_{n}\right)^{T}$ be the aggregation-associated vector such that $\omega_{i} \in[0,1], i=1,2, \ldots, n$, and $\sum_{i=1}^{n} \omega_{i}=1$; then, their aggregated value by the HILFOWG operator is still a HILFE, and

$$
\begin{aligned}
\operatorname{HILFOWG}\left(h_{1}, h_{2}, \ldots, h_{n}\right) & \\
= & \bigcup_{r_{\sigma(1)} \in h_{\sigma(1)}, r_{\sigma(2)} \in h_{\sigma(2)}, \ldots, r_{\sigma(n)} \in h_{\sigma(n)}}\{ \\
& \left(\prod _ { i = 1 } ^ { n } \mu \left(r_{\prod_{i=1}^{n} \theta\left(r_{\sigma(i)}\right)^{w_{i}},}^{\omega_{i}},\right.\right. \\
& \left.\left.\left.1-\prod_{i=1}^{n}\left(1-v\left(r_{\sigma(i)}\right)\right)^{\omega_{i}}\right)\right\rangle\right\} .
\end{aligned}
$$

Similar to the HILFOWA operator, the HILFOWG operator also has the properties of idempotency, boundedness, and commutativity under some conditions, which can be proved similar to Theorems 16, 17, and 24 .

Theorem 27. Let $h_{i}(i=1,2, \ldots, n)$ be a collection of HILFEs, let $\omega=\left(\omega_{1}, \omega_{2}, \ldots, \omega_{n}\right)^{T}$ be the aggregation-associated vector such that $\omega_{i} \in[0,1], i=1,2, \ldots, n$, and $\sum_{i=1}^{n} \omega_{i}=1$, and let $n$ be the balancing coefficient which plays a role of balance; then, one has

$$
\operatorname{HILFOWG}\left(h_{1}, h_{2}, \ldots, h_{n}\right) \leq \operatorname{HILFOWA}\left(h_{1}, h_{2}, \ldots, h_{n}\right)
$$

which can be proved similar to Theorem 21.

\subsection{Hesitant Intuitionistic Linguistic Fuzzy Hybrid Aggregation Operators}

Definition 28. Let $h_{i}(i=1,2, \ldots, n)$ be a collection of HILFEs, let $w=\left(w_{1}, w_{2}, \ldots, w_{n}\right)^{T}$ be the weight vector of them, with $w_{i} \in[0,1], i=1,2, \ldots, n$, and $\sum_{i=1}^{n} w_{i}=1$, and let $n$ be the balancing coefficient which plays a role of balance; then, based on the aggregation-associated vector $\omega=\left(\omega_{1}, \omega_{2}, \ldots, \omega_{n}\right)^{T}$ such that $\omega_{i} \in[0,1], i=1,2, \ldots, n$, and $\sum_{i=1}^{n} \omega_{i}=1$, the hesitant intuitionistic linguistic fuzzy hybrid average (HILFHA) operator is a mapping HILFHA: $H^{n} \rightarrow H$, and

$$
\operatorname{HILFHA}\left(h_{1}, h_{2}, \ldots, h_{n}\right)=\bigoplus_{i=1}^{n} \omega_{i} \dot{h}_{\sigma(i)},
$$

where $H$ is a hesitant intuitionistic linguistic fuzzy set. $\dot{h}_{\sigma(i)}$ is the $i$ th largest element of hesitant intuitionistic linguistic fuzzy weighted arguments $\dot{h}_{j}\left(\dot{h}_{j}=n w_{j} h_{j}, j=1,2, \ldots, n\right)$.

Theorem 29. Let $h_{i}(i=1,2, \ldots, n)$ be a collection of HILFEs, let $w=\left(w_{1}, w_{2}, \ldots, w_{n}\right)^{T}$ be the weight vector of them, with $w_{i} \in[0,1], i=1,2, \ldots, n$, and $\sum_{i=1}^{n} w_{i}=1$, and let $\omega$ $=\left(\omega_{1}, \omega_{2}, \ldots, \omega_{n}\right)^{T}$ be the aggregation-associated vector such that $\omega_{i} \in[0,1], i=1,2, \ldots, n$, and $\sum_{i=1}^{n} \omega_{i}=1$; then, their aggregated value by the HILFHA operator is still a HILFE, and

$$
\begin{aligned}
\operatorname{HILFHA}\left(h_{1}, h_{2}, \ldots, h_{n}\right) & \bigcup_{\dot{r}_{\sigma(1)} \in \dot{h}_{\sigma(1)}, \dot{r}_{\sigma(2)} \in \dot{h}_{\sigma(2)} \ldots, \dot{r}_{\sigma(n)} \in \dot{h}_{\sigma(n)}}\{ \\
& \left(1-\prod_{i=1}^{n}\left(1-\mu\left(\dot{r}_{\sum_{i=1}^{n} \omega_{i} \cdot \theta\left(\dot{r}_{\sigma(i)}\right)}\right)\right)^{\omega_{i},}\right. \\
& \left.\left.\left(\prod_{i=1}^{n} v\left(\dot{r}_{\sigma(i)}\right)^{\omega_{i}}\right)\right\rangle\right\} .
\end{aligned}
$$

In particular, if $\omega=(1 / n, 1 / n, \ldots, 1 / n)^{T}$, then the HILFHA operator reduces to the HILFWA operator in (8); if $w=$ $(1 / n, 1 / n, \ldots, 1 / n)^{T}$, then the HILFHA operator reduces to the HILFOWA operator in (28).

Similar to the HILFWA operator, the HILFHA operator also has the properties of idempotency and boundedness under some conditions, which can be proved similar to Theorems 16 and 17.

Definition 30. Let $h_{i}(i=1,2, \ldots, n)$ be a collection of HILFEs, let $w=\left(w_{1}, w_{2}, \ldots, w_{n}\right)^{T}$ be the weight vector of them, with $w_{i} \in[0,1], i=1,2, \ldots, n$, and $\sum_{i=1}^{n} w_{i}=1$, and let $n$ be the balancing coefficient which plays a role of balance; then, based on the aggregation-associated vector $\omega=\left(\omega_{1}, \omega_{2}, \ldots, \omega_{n}\right)^{T}$ such that $\omega_{i} \in[0,1], i=1,2, \ldots, n$, and $\sum_{i=1}^{n} \omega_{i}=1$, the hesitant intuitionistic linguistic fuzzy hybrid geometric (HILFHG) operator is a mapping HILFHG: $H^{n} \rightarrow H$, and

$$
\left.\operatorname{HILFHG}\left(h_{1}, h_{2}, \ldots, h_{n}\right)=\stackrel{\otimes}{i=1}_{i\left(h_{\sigma(i)}\right.}\right)^{\omega_{i}},
$$

where $H$ is a hesitant intuitionistic linguistic fuzzy set. $\ddot{h}_{\sigma(i)}$ is the $i$ th largest element of hesitant intuitionistic linguistic fuzzy weighted arguments $\ddot{h}_{j}\left(\ddot{h}_{j}=h_{j}^{n w_{j}}, j=1,2, \ldots, n\right)$.

Theorem 31. Let $h_{i}(i=1,2, \ldots, n)$ be a collection of HILFEs, let $w=\left(w_{1}, w_{2}, \ldots, w_{n}\right)^{T}$ be the weight vector of them, with $w_{i} \in[0,1], i=1,2, \ldots, n$, and $\sum_{i=1}^{n} w_{i}=1$, and let $\omega$ $=\left(\omega_{1}, \omega_{2}, \ldots, \omega_{n}\right)^{T}$ be the aggregation-associated vector such that $\omega_{i} \in[0,1], i=1,2, \ldots, n$, and $\sum_{i=1}^{n} \omega_{i}=1$; then, their aggregated value by the HILFHG operator is still a HILFE, and

$$
\begin{aligned}
\operatorname{HILFHG}\left(h_{1}, h_{2}, \ldots, h_{n}\right) & \left\{\bigcup_{\ddot{r}_{\sigma(1)} \in \ddot{h}_{\sigma(1)}, \ddot{r}_{\sigma(2)} \in \ddot{h}_{\sigma(2)}, \ldots, \ddot{r}_{\sigma(n)} \in \ddot{h}_{\sigma(n)}}\{\right. \\
& \left(\prod_{i=1}^{n} \mu\left(\ddot{r}_{\sigma(i)}\right)^{\omega_{i}},\right. \\
& 1-\prod_{i=1}^{n}\left(1-v\left(\ddot{r}_{\sigma(i)}\right)^{\omega_{i}},\right.
\end{aligned}
$$


In particular, if $\omega=(1 / n, 1 / n, \ldots, 1 / n)^{T}$, then the HILFHG operator reduces to the HILFWG operator in (20). If $w=$ $(1 / n, 1 / n, \ldots, 1 / n)^{T}$, then the HILFHG operator reduces to the HILFOWG operator in (32).

Similar to the HILFWG operator, the HILFHG operator also has the properties of idempotency and boundedness under some conditions, which can be proved similar to Theorems 16 and 17.

Theorem 32. Let $h_{i}(i=1,2, \ldots, n)$ be a collection of HILFEs, let $w=\left(w_{1}, w_{2}, \ldots, w_{n}\right)^{T}$ be the weight vector of them, with $w_{i} \in[0,1], i=1,2, \ldots, n$, and $\sum_{i=1}^{n} w_{i}=1$, let $\omega=\left(\omega_{1}, \omega_{2}\right.$, $\left.\ldots, \omega_{n}\right)^{T}$ be the aggregation-associated vector such that $\omega_{i} \in$ $[0,1], i=1,2, \ldots, n$, and $\sum_{i=1}^{n} \omega_{i}=1$, and let $n$ be the balancing coefficient which plays a role of balance; then, one has

$$
\operatorname{HILFHG}\left(h_{1}, h_{2}, \ldots, h_{n}\right) \leq \operatorname{HILFHA}\left(h_{1}, h_{2}, \ldots, h_{n}\right)
$$

which can be proved similar to Theorem 21 .

\subsection{Generalized Hesitant Intuitionistic Linguistic Fuzzy Weighted Aggregation Operators}

Definition 33. Let $h_{i}(i=1,2, \ldots, n)$ be a collection of HILFEs and let $w=\left(w_{1}, w_{2}, \ldots, w_{n}\right)^{T}$ be the weight vector of them, with $w_{i} \in[0,1], i=1,2, \ldots, n$, and $\sum_{i=1}^{n} w_{i}=1 ; \lambda$ is a parameter such that $\lambda \in(0,+\infty)$; then, the generalized hesitant intuitionistic linguistic fuzzy weighted average (GHILFWA) operator is a mapping GHILFWA: $H^{n} \rightarrow H$, and

$$
\operatorname{GHILFWA}_{\lambda}\left(h_{1}, h_{2}, \ldots, h_{n}\right)=\left(\underset{i=1}{\oplus} w_{i}\left(h_{i}\right)^{\lambda}\right)^{1 / \lambda},
$$

where $H$ is a hesitant intuitionistic linguistic fuzzy set.

Theorem 34. Let $h_{i}(i=1,2, \ldots, n)$ be a collection of HILFEs and let $w=\left(w_{1}, w_{2}, \ldots, w_{n}\right)^{T}$ be the weight vector of them, with $w_{i} \in[0,1], i=1,2, \ldots, n$, and $\sum_{i=1}^{n} w_{i}=1$; then, their aggregated value by the GHILFWA operator is still a HILFE, and

$$
\begin{aligned}
& \text { GHILFWA } A_{\lambda}\left(h_{1}, h_{2}, \ldots, h_{n}\right) \\
& \quad=\left(\underset{i=1}{\oplus} w_{i}\left(h_{i}\right)^{\lambda}\right)^{1 / \lambda} \\
& \quad=\bigcup_{r_{1} \in h_{1}, r_{2} \in h_{2}, \ldots, r_{n} \in h_{n}}\left\{\left\langles_{\left.\left.\left.\left(\sum_{i=1}^{n} w_{i} \cdot \theta\left(r_{i}\right)^{\lambda}\right)^{1 / \lambda},\left(1-\prod_{i=1}^{n}\left(1-\mu\left(r_{i}\right)^{\lambda}\right)^{w_{i}}\right)^{1 / \lambda}, 1-\left(1-\prod_{j=1}^{n}\left(1-\left(1-v\left(r_{i}\right)\right)^{\lambda}\right)^{w_{i}}\right)\right)^{1 / \lambda}\right)\right\}}\right.\right.
\end{aligned}
$$

In particular, if $\lambda=1$, then the GHILFWA operator reduces to the HILFWA operator in (8).

Similar to the HILFWA operator, the GHILFWA operator also has the properties of idempotency and boundedness under some conditions, which can be proved similar to Theorems 16 and 17.

Definition 35. Let $h_{i}(i=1,2, \ldots, n)$ be a collection of HILFEs and let $w=\left(w_{1}, w_{2}, \ldots, w_{n}\right)^{T}$ be the weight vector of them, with $w_{i} \in[0,1], i=1,2, \ldots, n$, and $\sum_{i=1}^{n} w_{i}=1 ; \lambda$ is a parameter such that $\lambda \in(0,+\infty)$; then, the generalized hesitant intuitionistic linguistic fuzzy weighted geometric (GHILFWG) operator is a mapping GHILFWG: $H^{n} \rightarrow H$, and

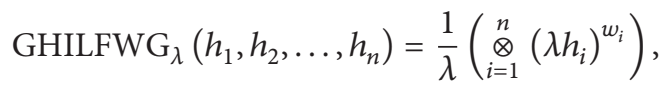

where $H$ is a hesitant intuitionistic linguistic fuzzy set.

Theorem 36. Let $h_{i}(i=1,2, \ldots, n)$ be a collection of HILFEs and let $w=\left(w_{1}, w_{2}, \ldots, w_{n}\right)^{T}$ be the weight vector of them, with $w_{i} \in[0,1], i=1,2, \ldots, n$, and $\sum_{i=1}^{n} w_{i}=1$; then, their aggregated value by the GHILFWG operator is still a HILFE, and

$$
\begin{aligned}
& \operatorname{GHILFWG}_{\lambda}\left(h_{1}, h_{2}, \ldots, h_{n}\right) \\
& =\bigcup_{r_{1} \in h_{1}, r_{2} \in h_{2}, \ldots, r_{n} \in h_{n}}\left\{\left\langles_{\left(\sum_{i=1}^{n} w_{i} \cdot \theta\left(r_{i}\right)^{\lambda}\right)^{1 / \lambda},}\right.\right. \\
& \left(1-\left(1-\prod_{j=1}^{n}\left(1-\left(1-\mu\left(r_{i}\right)\right)^{\lambda}\right)^{w_{i}}\right)^{1 / \lambda},\right. \\
& \left.\left.\left.\left(1-\prod_{i=1}^{n}\left(1-v\left(r_{i}\right)^{\lambda}\right)^{w_{i}}\right)^{1 / \lambda}\right)\right\rangle\right\} .
\end{aligned}
$$

In particular, if $\lambda=1$, then the GHILFWG operator reduces to the HILFWG operator in (20).

Similar to the HILFWG operator, the GHILFWG operator also has the properties of idempotency and boundedness under some conditions, which can be proved similar to Theorems 16 and 17. 
Theorem 37. Let $h_{i}(i=1,2, \ldots, n)$ be a collection of HILFEs, let $w=\left(w_{1}, w_{2}, \ldots, w_{n}\right)^{T}$ be the weight vector of them, with $w_{i} \in[0,1], i=1,2, \ldots, n$, and $\sum_{i=1}^{n} w_{i}=1$, and let $n$ be the balancing coefficient which plays a role of balance; then, one has

$$
\operatorname{GHILFWG}\left(h_{1}, h_{2}, \ldots, h_{n}\right) \leq \operatorname{GHILFWA}\left(h_{1}, h_{2}, \ldots, h_{n}\right)
$$

which can be proved similar to Theorem 21.

\subsection{Generalized Hesitant Intuitionistic Linguistic Fuzzy Ordered Weighted Aggregation Operators}

Definition 38. Let $h_{i}(i=1,2, \ldots, n)$ be a collection of HILFEs and let $\omega=\left(\omega_{1}, \omega_{2}, \ldots, \omega_{n}\right)^{T}$ be the aggregation-associated vector such that $\omega_{i} \in[0,1], i=1,2, \ldots, n$, and $\sum_{i=1}^{n} \omega_{i}=1$; $\lambda$ is a parameter such that $\lambda \in(0,+\infty)$; then, the generalized hesitant intuitionistic linguistic fuzzy ordered weighted average (GHILFOWA) operator is a mapping GHILFOWA: $H^{n} \rightarrow H$, and

$$
\operatorname{GHILFOWA}_{\lambda}\left(h_{1}, h_{2}, \ldots, h_{n}\right)=\left(\underset{i=1}{\oplus} w_{i}\left(h_{\sigma(i)}\right)^{\lambda}\right)^{1 / \lambda}
$$

where $H$ is a hesitant intuitionistic linguistic fuzzy set. $h_{\sigma(i)}$ is the $i$ th largest element in $h_{i}(i=1,2, \ldots, n)$.

Theorem 39. Let $h_{i}(i=1,2, \ldots, n)$ be a collection of HILFEs and let $\omega=\left(\omega_{1}, \omega_{2}, \ldots, \omega_{n}\right)^{T}$ be the aggregation-associated vector such that $\omega_{i} \in[0,1], i=1,2, \ldots, n$, and $\sum_{i=1}^{n} \omega_{i}=1$; then, their aggregated value by the GHILFOWA operator is still a HILFE, and

$$
\begin{aligned}
& \operatorname{GHILFOWA}_{\lambda}\left(h_{1}, h_{2}, \ldots, h_{n}\right) \\
& =\bigcup_{r_{1} \in h_{1}, r_{2} \in h_{2}, \ldots, r_{n} \in h_{n}}\left\{\left\langle s_{\left(\sum_{i=1}^{n} w_{i} \cdot \theta\left(r_{\sigma(i)}\right)^{\lambda}\right)^{1 / \lambda}}\left(\left(1-\prod_{i=1}^{n}\left(1-\mu\left(r_{\sigma(i)}\right)^{\lambda}\right)^{w_{i}}\right)^{1 / \lambda}, 1-\left(1-\prod_{j=1}^{n}\left(1-\left(1-v\left(r_{\sigma(i)}\right)\right)^{\lambda}\right)^{w_{i}}\right)^{1 / \lambda}\right)\right\rangle^{2} .\right.
\end{aligned}
$$

In particular, if $\lambda=1$, then the GHILFOWA operator reduces to the HILFOWA operator in (28).

Similar to the HILFOWA operator, the GHILFOWA operator also has the properties of idempotency, boundedness, and commutativity under some conditions, which can be proved similar to Theorems 16, 17, and 24 .

Definition 40. Let $h_{i}(i=1,2, \ldots, n)$ be a collection of HILFEs and let $\omega=\left(\omega_{1}, \omega_{2}, \ldots, \omega_{n}\right)^{T}$ be the aggregationassociated vector such that $\omega_{i} \in[0,1], i=1,2, \ldots, n$, and $\sum_{i=1}^{n} \omega_{i}=1 ; \lambda$ is a parameter such that $\lambda \in(0,+\infty)$; then, the generalized hesitant intuitionistic linguistic fuzzy ordered weighted geometric (GHILFOWG) operator is a mapping GHILFOWG: $H^{n} \rightarrow H$, and

$$
\operatorname{GHILFOWG}_{\lambda}\left(h_{1}, h_{2}, \ldots, h_{n}\right)=\frac{1}{\lambda}\left(\stackrel{\otimes}{\otimes}_{i=1}^{n}\left(\lambda h_{\sigma(i)}\right)^{w_{i}}\right),
$$

where $H$ is a hesitant intuitionistic linguistic fuzzy set. $h_{\sigma(i)}$ is the $i$ th largest element in $h_{i}(i=1,2, \ldots, n)$.

Theorem 41. Let $h_{i}(i=1,2, \ldots, n)$ be a collection of HILFEs and let $\omega=\left(\omega_{1}, \omega_{2}, \ldots, \omega_{n}\right)^{T}$ be the aggregation-associated vector such that $\omega_{i} \in[0,1], i=1,2, \ldots, n$, and $\sum_{i=1}^{n} \omega_{i}=1$; then, their aggregated value by the GHILFOWG operator is still a HILFE, and

$$
\begin{aligned}
& \operatorname{GHILFOWG}_{\lambda}\left(h_{1}, h_{2}, \ldots, h_{n}\right) \\
& =\bigcup_{r_{1} \in h_{1}, r_{2} \in h_{2}, \ldots, r_{n} \in h_{n}}\left\{\left\langle s_{\left(\sum_{i=1}^{n} w_{i} \cdot \theta\left(r_{\sigma(i)}\right)^{\lambda}\right)^{1 / \lambda}},\left(1-\left(1-\prod_{j=1}^{n}\left(1-\left(1-v\left(r_{\sigma(i)}\right)\right)^{\lambda}\right)^{w_{i}}\right)^{1 / \lambda},\left(1-\prod_{i=1}^{n}\left(1-\mu\left(r_{\sigma(i)}\right)^{\lambda}\right)^{w_{i}}\right)^{1 / \lambda}\right)\right\}^{\prime \lambda} .\right.
\end{aligned}
$$

In particular, if $\lambda=1$, then the GHILFOWG operator reduces to the HILFOWG operator in (32).

Similar to the HILFOWG operator, the GHILFOWG operator also has the properties of idempotency, boundedness, and commutativity under some conditions, which can be proved similar to Theorems 16, 17, and 24 .
Theorem 42. Let $h_{i}(i=1,2, \ldots, n)$ be a collection of HILFEs, let $\omega=\left(\omega_{1}, \omega_{2}, \ldots, \omega_{n}\right)^{T}$ be the aggregation-associated vector such that $\omega_{i} \in[0,1], i=1,2, \ldots, n$, and $\sum_{i=1}^{n} \omega_{i}=1$, and let $n$ be the balancing coefficient which plays a role of balance; then, one has

$\operatorname{GHILFOWG}\left(h_{1}, h_{2}, \ldots, h_{n}\right) \leq \operatorname{GHILFOWA}\left(h_{1}, h_{2}, \ldots, h_{n}\right)$

which can be proved similar to Theorem 21. 


\section{An Approach for Satisfaction Evaluation with Hesitant Intuitionistic Linguistic Fuzzy Information}

For a MADM problem, let $A=\left\{A_{1}, A_{2}, \ldots, A_{m}\right\}$ be a finite set of $m$ alternatives and let $C=\left\{C_{1}, C_{2}, \ldots, C_{n}\right\}$ be the set of $n$ attributes. Suppose that all values assigned to alternatives with respect to attributes are expressed by a hesitant intuitionistic linguistic fuzzy decision matrix denoted by $H=\left(h_{i j}\right)_{m \times n}$, where elements $h_{i j}=$ $\bigcup_{\left\langle s_{\theta\left(h_{i j}\right)},\left(u\left(h_{i j}\right), v\left(h_{i j}\right)\right)\right\rangle \in h_{i j}}\left\{\left\langle s_{\theta\left(h_{i j}\right)},\left(u\left(h_{i j}\right), v\left(h_{i j}\right)\right)\right\rangle\right\}$ are HILFEs provided for the rating of the alternative $A_{i}(i=1,2, \ldots, m)$ with respect to the attribute $C_{j}(j=1,2, \ldots, n)$, with $s_{\theta\left(h_{i j}\right)} \in S=\left\{s_{0}, s_{1}, \ldots, s_{g}\right\}$. If the information about attribute weights is completely known as $w=\left(w_{1}, w_{2}, \ldots, w_{n}\right)^{T}$, with $w_{j} \in[0,1], j=1,2, \ldots, n$, and $\sum_{j=1}^{n} w_{j}=1$, then to determine the most desirable alternative(s), the HILFWA operator or the HILFWG operator is utilized to propose an approach to MADM under hesitant intuitionistic linguistic fuzzy environment, which involves the following steps.

Step 1. Aggregate the hesitant intuitionistic linguistic fuzzy assessment values $h_{i j}$ of the alternative $A_{i}(i=1,2, \ldots, m)$ on all attributes $C_{j}(j=1,2, \ldots, n)$ into the overall assessment value $h_{i}$ of the alternative $A_{i}(i=1,2, \ldots, m)$ based on the HILFWA operator or the HILFWG operator in (50) and (51), respectively. Consider

$$
\begin{aligned}
& h_{i} \\
& =\operatorname{HILFWA}\left(h_{i 1}, h_{i 2}, \ldots, h_{i n}\right)=\bigoplus_{j=1}^{n} w_{j} h_{i j} \\
& =\bigcup_{\left\langle s_{\theta\left(h_{i j}\right)},\left(u\left(h_{i j}\right), v\left(h_{i j}\right)\right)\right\rangle \in h_{i j}}\left\{\left\langles_{\sum_{j=1}^{n} w_{j} \cdot \theta\left(h_{i j}\right)},\right.\right. \\
& \\
& \qquad 1-\prod_{j=1}^{n}\left(1-\mu\left(h_{i j}\right)\right)^{w_{j},}, \\
& \left.\left.\left.\prod_{j=1}^{n} v\left(h_{i j}\right)^{w_{j}}\right)\right\rangle\right\},
\end{aligned}
$$

or

$$
\begin{aligned}
& h_{i} \\
& =\operatorname{HILFWG}\left(h_{i 1}, h_{i 2}, \ldots, h_{i n}\right)=\bigotimes_{j=1}^{n} h_{i j}^{w_{j}} \\
& =\bigcup_{\left\langle s_{\theta\left(h_{i j}\right)},\left(u\left(h_{i j}\right), v\left(h_{i j}\right)\right)\right\rangle \in h_{i j}}\left\{\left\langles_{\prod_{j=1}^{n} \theta\left(h_{i j}\right)^{w_{j}},}\right.\right. \\
& \left(\prod_{j=1}^{n} \mu\left(h_{i j}\right)^{w_{j},},\right.
\end{aligned}
$$

$$
\left.\left.\left.1-\prod_{j=1}^{n}\left(1-v\left(h_{i j}\right)\right)^{w_{j}}\right)\right\rangle\right\}
$$

where $h_{i}$ is in the form of HILFEs and it can be denoted by $h_{i}=\bigcup_{\left\langle s_{\theta\left(h_{i}\right)},\left(u\left(h_{i}\right), v\left(h_{i}\right)\right)\right\rangle \in h_{i}}\left\{\left\langle s_{\theta\left(h_{i}\right)},\left(u\left(h_{i}\right), v\left(h_{i}\right)\right)\right\rangle\right\}$.

Step 2. Calculate the score values $S\left(h_{i}\right)$ of overall assessment values $h_{i}(i=1,2, \ldots, m)$ by

$$
S\left(h_{i}\right)=\frac{1}{\# h_{i}} \sum_{\left\langle s_{\theta\left(h_{i}\right)},\left(u\left(h_{i}\right), v\left(h_{i}\right)\right)\right\rangle \in h_{i}} \frac{\theta\left(h_{i}\right)\left(1+\mu\left(h_{i}\right)-v\left(h_{i}\right)\right)}{2 g},
$$

where $\# h_{i}$ is the number of ILVs in $h_{i}$ and $g+1$ is the cardinality of linguistic term set $S$. If there is no difference between two score values $S\left(h_{i}\right)$ and $S\left(h_{k}\right)$, then we need to calculate the accuracy degrees $P\left(h_{i}\right)$ and $P\left(h_{k}\right)$ of the overall assessment values $h_{i}$ and $h_{k}(i, k=1,2, \ldots, m$ and $i \neq k)$, respectively, according to

$$
P\left(h_{i}\right)=\frac{1}{\# h_{i}} \sum_{\left\langle s_{\theta\left(h_{i}\right)},\left(u\left(h_{i}\right), v\left(h_{i}\right)\right)\right\rangle \in h_{i}} \frac{\theta\left(h_{i}\right)\left(\mu\left(h_{i}\right)+v\left(h_{i}\right)\right)}{2 g} .
$$

Step 3. Rank all feasible alternatives $A_{i}(i=1,2, \ldots, m)$ according to Theorem 4 and select the most desirable alternative(s).

Step 4. End.

\section{Numerical Example}

In this section, a practical example of satisfaction evaluation for milk products is adapted to illustrate the application of the MADM method proposed in Section 5 and to demonstrate its feasibility and effectiveness in a realistic scenario.

To strengthen the competitiveness and enlarge the product lines, a milk and dairy company needs to know the consumer satisfaction of its products at first, so the market department organizes investigations in several supermarkets. There is a panel with four milk products: (1) $A_{1}$ is the milk beverage; (2) $A_{2}$ is the yoghourt; (3) $A_{3}$ is the cheese; (4) $A_{4}$ is the pasteurized milk. The milk and dairy company must make a decision according to the following four attributes: (1) $C_{1}$ is the price; (2) $C_{2}$ is the taste; (3) $C_{3}$ is the packaging; (4) $C_{4}$ is the storability, whose weight vector is given as $w=(0.30,0.35,0.10,0.25)^{T}$. The four possible alternatives $\left\{A_{1}, A_{2}, A_{3}, A_{4}\right\}$ are evaluated by using the linguistic term set $S=\left\{s_{0}=\right.$ extremely poor, $s_{1}=$ very poor, $s_{2}=$ poor, $s_{3}=$ fair, $s_{4}=$ good, $s_{5}=$ very good, $s_{6}=$ extremely good $\}$ under the above four attributes. The hesitant intuitionistic linguistic fuzzy decision matrix $H=\left(h_{i j}\right)_{4 \times 4}$ is constructed as shown in Table 1 . 


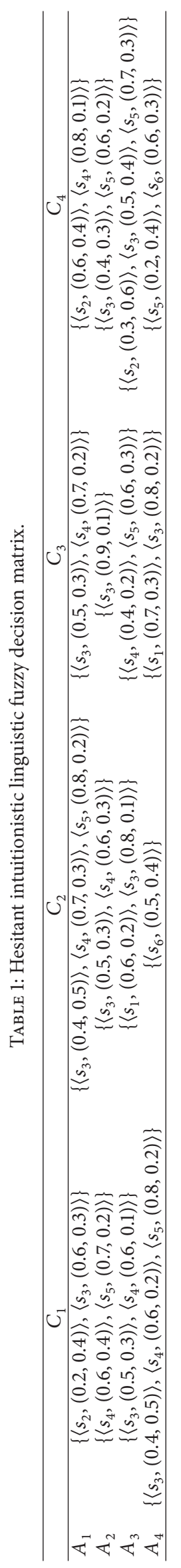


In the following, we utilize the proposed MADM method to rank the milk products according to the customer satisfaction evaluation with hesitant intuitionistic linguistic fuzzy information.

Step 1. Aggregate the hesitant intuitionistic linguistic fuzzy assessment values $h_{i j}$ of the milk products $A_{i}(i=1,2,3,4)$ on all attributes $C_{j}(j=1,2,3,4)$ into the overall assessment value $h_{i}$ of the milk products $A_{i}(i=1,2,3,4)$ based on the HILFWA operator in (50). Take the milk product $A_{1}$ for example; we have

$$
\begin{aligned}
h_{1} & \\
= & \operatorname{HILFWA}\left(h_{11}, h_{12}, h_{13}, h_{14}\right) \\
= & \left\langle s_{\sum_{j=1}^{4} w_{j} \cdot \theta\left(h_{1 j}\right)}, \quad\left\{\left(1-\prod_{j=1}^{4}\left(1-\mu\left(h_{1 j}\right)\right)^{w_{j}},\right.\right.\right. \\
& \left\langle s_{\theta\left(h_{1 j}\right)},\left(u\left(h_{1 j}\right), v\left(h_{1 j}\right)\right)\right\rangle \in h_{1 j}
\end{aligned}
$$

Similarly, the overall assessment values $h_{i}$ of other milk products $A_{i}(i=2,3,4)$ can be obtained. Consider

$$
\begin{aligned}
h_{2} & \\
= & \left\{\left\langle s_{3.30},(0.5833,0.2930)\right\rangle,\left\langle s_{3.80},(0.6235,0.2648)\right\rangle,\right. \\
& \left\langle s_{3.65},(0.6146,0.2930)\right\rangle,\left\langle s_{4.15},(0.6518,0.2648)\right\rangle, \\
& \left\langle s_{3.60},(0.6178,0.2380)\right\rangle,\left\langle s_{4.10},(0.6546,0.2151)\right\rangle,
\end{aligned}
$$

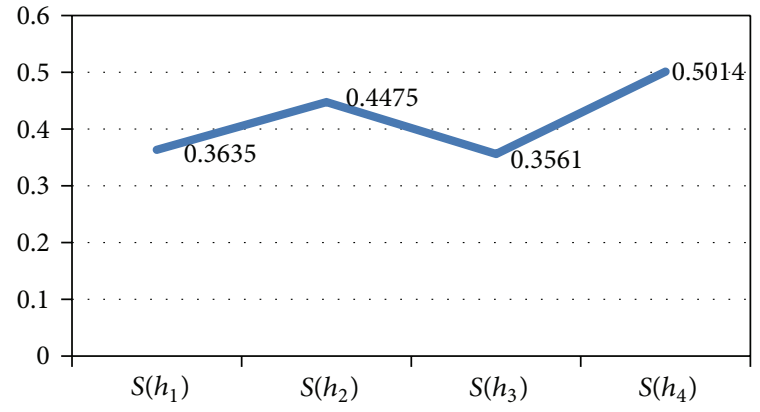

FIgURE 1: Score values $S\left(h_{i}\right)$ of the milk products.

$\left.\left\langle s_{3.95},(0.6465,0.2380)\right\rangle,\left\langle s_{4.45},(0.6806,0.2151)\right\rangle\right\} ;$ $h_{3}$

$$
\begin{aligned}
& =\left\{\left\langle s_{2.15},(0.4877,0.2973)\right\rangle,\left\langle s_{2.40},(0.5291,0.2686)\right\rangle,\right. \\
& \left\langle s_{2.90},(0.5855,0.2500)\right\rangle,\left\langle s_{2.25},(0.5081,0.3096)\right\rangle, \\
& \left\langle s_{2.50},(0.5478,0.2797)\right\rangle,\left\langle s_{3.00},(0.6020,0.2603)\right\rangle \text {, } \\
& \left\langle s_{2.85},(0.5981,0.2332)\right\rangle,\left\langle s_{3.10},(0.6305,0.2107)\right\rangle \text {, } \\
& \left\langle s_{3.60},(0.6748,0.1961)\right\rangle,\left\langle s_{2.95},(0.6140,0.2429)\right\rangle \text {, } \\
& \left\langle s_{3.20},(0.6452,0.2195)\right\rangle,\left\langle s_{3.70},(0.6877,0.2042)\right\rangle \text {, } \\
& \left\langle s_{2.45},(0.5209,0.2138)\right\rangle,\left\langle s_{2.70},(0.5595,0.1932)\right\rangle, \\
& \left\langle s_{3.20},(0.6124,0.1798)\right\rangle,\left\langle s_{2.55},(0.5399,0.2226)\right\rangle, \\
& \left\langle s_{2.80},(0.5771,0.2012)\right\rangle,\left\langle s_{3.30},(0.6278,0.1872)\right\rangle, \\
& \left\langle s_{3.15},(0.6241,0.1677)\right\rangle,\left\langle s_{3.40},(0.6544,0.1516)\right\rangle \text {, } \\
& \left\langle s_{3.90},(0.6959,0.1411)\right\rangle,\left\langle s_{3.25},(0.6390,0.1747)\right\rangle \text {, } \\
& \left.\left\langle s_{3.50},(0.6682,0.1578)\right\rangle,\left\langle s_{4.00},(0.7079,0.1469)\right\rangle\right\} \text {; }
\end{aligned}
$$

$h_{4}$

$$
\begin{aligned}
& =\left\{\left\langle s_{4.35},(0.4356,0.4156)\right\rangle,\left\langle s_{4.60},(0.5254,0.3867)\right\rangle,\right. \\
& \left\langle s_{4.55},(0.4580,0.3991)\right\rangle,\left\langle s_{4.80},(0.5443,0.3714)\right\rangle \text {, } \\
& \left\langle s_{4.65},(0.5003,0.3157)\right\rangle,\left\langle s_{4.90},(0.5798,0.2938)\right\rangle, \\
& \left\langle s_{4.85},(0.5201,0.3031)\right\rangle,\left\langle s_{5.10},(0.5965,0.2821)\right\rangle \text {, } \\
& \left\langle s_{4.95},(0.5941,0.3157)\right\rangle,\left\langle s_{5.20},(0.6587,0.2938)\right\rangle \text {, } \\
& \left.\left\langle s_{5.15},(0.6102,0.3031)\right\rangle,\left\langle s_{5.40},(0.6722,0.2821)\right\rangle\right\} \text {. }
\end{aligned}
$$

Step 2. Calculate the score values $S\left(h_{i}\right)$ of overall assessment values $h_{i}(i=1,2,3,4)$ by $(52)$, which are shown in Figure 1.

Step 3. Rank all feasible milk products $A_{i}(i=1,2,3,4)$ in accordance with the descending order of corresponding score values. Since $S\left(h_{4}\right)>S\left(h_{2}\right)>S\left(h_{1}\right)>S\left(h_{3}\right)$, thus the ranking 
of all milk products is obtained as $A_{4}>A_{2}>A_{1}>A_{3}$, where the symbol " $>$ " means "superior to." Therefore, the most desirable milk product is $A_{4}$ (pasteurized milk).

If we utilize the HILFWG operator in (51) to aggregate the hesitant intuitionistic linguistic fuzzy assessment values $h_{i j}$ of the milk products $A_{i}(i=1,2,3,4)$ on all attributes $C_{j}$ $(j=1,2,3,4)$ into the overall assessment value $\widehat{h}_{i}$ of the milk products $A_{i}(i=1,2,3,4)$ in Step 1 , we can obtain

$$
\begin{aligned}
\widehat{h}_{1} & \\
= & \left\langle\left\langle s_{2.40},(0.3677,0.4283)\right\rangle,\left\langle s_{2.85},(0.3951,0.3674)\right\rangle,\right. \\
& \left\langle s_{2.47},(0.3803,0.4207)\right\rangle,\langle s 2.94,(0.4086,0.3589)\rangle, \\
& \left\langle s_{2.65},(0.4472,0.3569)\right\rangle,\left\langle s_{3.16},(0.4806,0.2883)\right\rangle, \\
& \left\langle s_{2.73},(0.4625,0.3483)\right\rangle,\left\langle s_{3.25},(0.4970,0.2787)\right\rangle, \\
& \left\langle s_{2.87},(0.4686,0.3261)\right\rangle,\left\langle s_{3.41},(0.5036,0.2542)\right\rangle, \\
& \left\langle s_{2.95},(0.4847,0.3171)\right\rangle,\left\langle s_{3.51},(0.5208,0.2442)\right\rangle, \\
& \left\langle s_{2.71},(0.5112,0.4013)\right\rangle,\left\langle s_{3.22},(0.5493,0.3374)\right\rangle, \\
& \left\langle s_{2.79},(0.5287,0.3932)\right\rangle,\left\langle s_{3.32},(0.5681,0.3285)\right\rangle, \\
& \left\langle s_{3.00},(0.6218,0.3265)\right\rangle,\left\langle s_{3.57},(0.6682,0.2546)\right\rangle, \\
& \left\langle s_{3.09},(0.6431,0.3174)\right\rangle,\left\langle s_{3.67},(0.6911,0.2446)\right\rangle, \\
& \left\langle s_{3.24},(0.6516,0.2942)\right\rangle,\left\langle s_{3.85},(0.7002,0.2189)\right\rangle, \\
& \left.\left\langle s_{3.34},(0.6739,0.2848)\right\rangle,\left\langle s_{3.97},(0.7241,0.2084)\right\rangle\right\} ;
\end{aligned}
$$$$
\widehat{h}_{2}
$$$$
=\left\{\left\langle s_{3.27},(0.5297,0.3146)\right\rangle,\left\langle s_{3.72},(0.5862,0.2914)\right\rangle,\right.
$$$$
\left\langle s_{3.62},(0.5646,0.3146)\right\rangle,\left\langle s_{4.11},(0.6248,0.2914)\right\rangle,
$$$$
\left\langle s_{3.50},(0.5548,0.2528)\right\rangle,\left\langle s_{3.97},(0.6139,0.2275)\right\rangle,
$$$$
\left.\left\langle s_{3.87},(0.5913,0.2528)\right\rangle,\left\langle s_{4.39},(0.6544,0.2275)\right\rangle\right\} ;
$$$$
\widehat{h}_{3}
$$$$
=\left\{\left\langle s_{1.90},(0.4587,0.3537)\right\rangle,\left\langle s_{2.10},(0.5212,0.2848)\right\rangle,\right.
$$$$
\left\langle s_{2.39},(0.5669,0.2566)\right\rangle,\left\langle s_{1.94},(0.4777,0.3623)\right\rangle,
$$$$
\left\langle s_{2.15},(0.5428,0.2942)\right\rangle,\left\langle s_{2.44},(0.5904,0.2665)\right\rangle \text {, }
$$$$
\left\langle s_{2.79},(0.5073,0.3265)\right\rangle,\left\langle s_{3.09},(0.5764,0.2546)\right\rangle \text {, }
$$$$
\left\langle s_{3.51},(0.6270,0.2254)\right\rangle,\left\langle s_{2.85},(0.5283,0.3354)\right\rangle,
$$$$
\left\langle s_{3.16},(0.6002,0.2645)\right\rangle,\left\langle s_{3.59},(0.6529,0.2356)\right\rangle,
$$$$
\left\langle s_{2.07},(0.4845,0.3031)\right\rangle,\left\langle s_{2.29},(0.5505,0.2287)\right\rangle,
$$$$
\left\langle s_{2.60},(0.5988,0.1984)\right\rangle,\left\langle s_{2.12},(0.5045,0.3123)\right\rangle \text {, }
$$$$
\left\langle s_{2.34},(0.5733,0.2390)\right\rangle,\left\langle s_{2.66},(0.6236,0.2091)\right\rangle \text {, }
$$

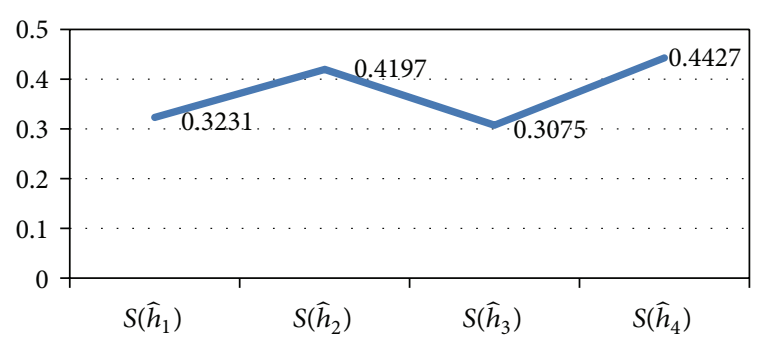

FIgURE 2: Score values $S\left(\widehat{h}_{i}\right)$ of the milk products.

TABLE 2: Hesitant fuzzy linguistic decision matrix.

\begin{tabular}{ccccc}
\hline & $C_{1}$ & $C_{2}$ & $C_{3}$ & $C_{4}$ \\
\hline$A_{1}$ & $\left\{s_{2}, s_{3}\right\}$ & $\left\{s_{3}, s_{4}, s_{5}\right\}$ & $\left\{s_{3}, s_{4}\right\}$ & $\left\{s_{2}, s_{4}\right\}$ \\
$A_{2}$ & $\left\{s_{4}, s_{5}\right\}$ & $\left\{s_{3}, s_{4}\right\}$ & $\left\{s_{3}\right\}$ & $\left\{s_{3}, s_{5}\right\}$ \\
$A_{3}$ & $\left\{s_{3}, s_{4}\right\}$ & $\left\{s_{1}, s_{3}\right\}$ & $\left\{s_{4}, s_{5}\right\}$ & $\left\{s_{2}, s_{3}, s_{5}\right\}$ \\
$A_{4}$ & $\left\{s_{3}, s_{4}, s_{5}\right\}$ & $\left\{s_{6}\right\}$ & $\left\{s_{1}, s_{3}\right\}$ & $\left\{s_{5}, s_{6}\right\}$ \\
\hline
\end{tabular}

$$
\begin{aligned}
& \left\langle s_{3.04},(0.5358,0.2738)\right\rangle,\left\langle s_{3.37},(0.6088,0.1963)\right\rangle, \\
& \left\langle s_{3.82},(0.6622,0.1647)\right\rangle,\left\langle s_{3.11},(0.5580,0.2834)\right\rangle, \\
& \left.\left\langle s_{3.44},(0.6340,0.2069)\right\rangle,\left\langle s_{3.91},(0.6896,0.1758)\right\rangle\right\} ;
\end{aligned}
$$

$\widehat{h}_{4}$

$$
\begin{aligned}
= & \left\{\left\langle s_{3.89},(0.3846,0.4231)\right\rangle,\left\langle s_{4.07},(0.5062,0.4004)\right\rangle,\right. \\
& \left\langle s_{4.34},(0.3898,0.4154)\right\rangle,\left\langle s_{4.55},(0.5130,0.3924)\right\rangle, \\
& \left\langle s_{4.24},(0.4344,0.3358)\right\rangle,\left\langle s_{4.44},(0.5717,0.3097)\right\rangle, \\
& \left\langle s_{4.74},(0.4402,0.3268)\right\rangle,\left\langle s_{4.96},(0.5793,0.3004)\right\rangle, \\
& \left\langle s_{4.54},(0.4735,0.3358)\right\rangle,\left\langle s_{4.75},(0.6232,0.3097)\right\rangle, \\
& \left.\left\langle s_{5.06},(0.4799,0.3268)\right\rangle,\left\langle s_{5.30},(0.6316,0.3004)\right\rangle\right\} .
\end{aligned}
$$

Then calculate the score values $S\left(\widehat{h}_{i}\right)$ of overall assessment values $\widehat{h}_{i}(i=1,2,3,4)$ by $(52)$, which are shown in Figure 2.

Since $S\left(\widehat{h}_{4}\right)>S\left(\widehat{h}_{2}\right)>S\left(\widehat{h}_{1}\right)>S\left(\widehat{h}_{3}\right)$, thus the ranking of all milk products is obtained as $A_{4}>A_{2}>A_{1}>A_{3}$. Therefore, the most desirable milk product is $A_{4}$ (pasteurized milk) as well.

Additionally, by comparing $S\left(\widehat{h}_{i}\right)(i=1,2,3,4)$ obtained by the HILFWG operator with $S\left(h_{i}\right)$ obtained by the HILFWA operator, we can find that $S\left(\widehat{h}_{i}\right)<S\left(h_{i}\right)$ for all $i=1,2,3,4$, which confirms the proof of $\operatorname{HILFWG}\left(h_{1}, h_{2}, \ldots, h_{n}\right) \leq$ $\operatorname{HILFWA}\left(h_{1}, h_{2}, \ldots, h_{n}\right)$ in Theorem 21.

For the same problem, if we utilize the decision making method based on the hesitant fuzzy linguistic term set proposed by Rodriguez et al. [34], then the hesitant fuzzy linguistic matrix is constructed as shown in Table 2.

Then, we can obtain the overall assessment value $\hbar_{i}$ of the milk products $A_{i}(i=1,2,3,4)$ by the hesitant fuzzy linguistic 


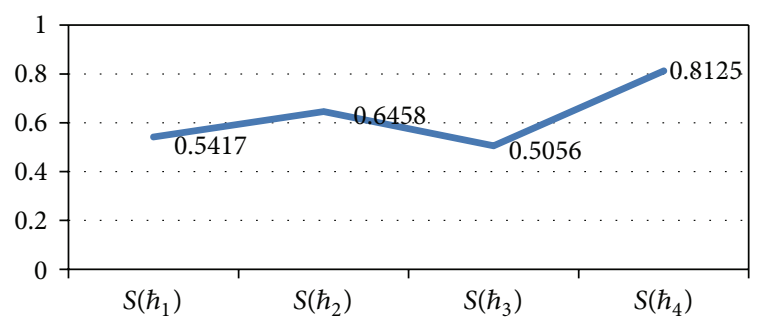

FIgURE 3: Score values $S\left(\hbar_{i}\right)$ of the milk products.

weighted averaging (HFLWA) operator proposed by Zhang and $\mathrm{Wu}$ [35]. Consider

$$
\begin{aligned}
& \hbar_{1}=\left\{s_{2.45}, s_{2.95}, s_{2.55}, s_{3.05}, s_{2.80}, s_{3.30}, s_{2.90},\right. \\
& s_{3.40}, s_{3.15}, s_{3.65}, s_{3.25}, s_{3.75}, s_{2.75} \text {, } \\
& s_{3.25}, s_{2.85}, s_{3.35}, s_{3.10}, s_{3.60}, s_{3.20} \text {, } \\
& \left.s_{3.70}, s_{3.45}, s_{3.95}, s_{3.55}, s_{4.05}\right\} \text {; } \\
& \hbar_{2}=\left\{s_{3.30}, s_{3.80}, s_{3.65}, s_{4.15}, s_{3.60}, s_{4.10}, s_{3.95}, s_{4.45}\right\} ; \\
& \hbar_{3}=\left\{s_{2.15}, s_{2.40}, s_{2.90}, s_{2.25}, s_{2.50}, s_{3.00}, s_{2.85}, s_{3.10},\right. \\
& s_{3.60}, s_{2.95}, s_{3.20}, s_{3.70}, s_{2.45}, s_{2.70}, s_{3.20}, s_{2.55} \text {, } \\
& \left.s_{2.80}, s_{3.30}, s_{3.15}, s_{3.40}, s_{3.90}, s_{3.25}, s_{3.50}, s_{4.00}\right\} ; \\
& \hbar_{4}=\left\{s_{4.35}, s_{4.60}, s_{4.55}, s_{4.80}, s_{4.65}, s_{4.90}, s_{4.85}, s_{5.10}\right. \text {, } \\
& \left.s_{4.95}, s_{5.20}, s_{5.15}, s_{5.40}\right\} \text {. }
\end{aligned}
$$

Thus, we can obtain the score values of the milk products $A_{i}(i=1,2,3,4)$ as shown in Figure 3.

Since $S\left(\hbar_{4}\right)>S\left(\hbar_{2}\right)>S\left(\hbar_{1}\right)>S\left(\hbar_{3}\right)$, thus the ranking of all milk products is obtained as $A_{4}>A_{2}>A_{1}>A_{3}$. Therefore, the most desirable milk product is $A_{4}$ (pasteurized milk) as well, which demonstrates the feasibility and validity of the method proposed in this paper. Moreover, we can know the membership degree and the nonmembership degree of the possible assessment value from the results obtained by the new methods proposed in this paper.

\section{Conclusions}

With respect to MADM problems in which the attribute values take the form of HILFE, this paper studies the MADM approach under hesitant intuitionistic linguistic fuzzy environment. Firstly, the concept, operational laws, and comparison laws of HILFE are proposed. Then, some aggregation operators are developed for aggregating the hesitant intuitionistic linguistic fuzzy information, such as hesitant intuitionistic linguistic fuzzy weighted aggregation operators, hesitant intuitionistic linguistic fuzzy ordered weighted aggregation operators, hesitant intuitionistic linguistic fuzzy hybrid aggregation operators, generalized hesitant intuitionistic linguistic fuzzy weighted aggregation operators, and generalized hesitant intuitionistic linguistic fuzzy ordered weighted aggregation operators. Based on the proposed
HILFWA operator and HILFWG operator, an approach is proposed to solve MADM problems under hesitant intuitionistic linguistic fuzzy environment. Finally, a practical example is given to illustrate the application of the proposed method. The main advantage of our approach is that it can describe the uncertain information by several intuitionistic linguistic variablesin which linguistic variables demonstrate whether an attribute is good or bad in qualitative and intuitionistic fuzzy numbers are adopted to demonstrate how much degree that an attribute value belongs and does not belong to a linguistic variable in quantitative. In future research, we will focus on expanding the hesitant intuitionistic linguistic decision-making approach to other domains such as supplier selection, location choice, project selection, and green supply chain evaluation.

\section{Conflict of Interests}

The authors declare that there is no conflict of interests regarding the publication of this paper.

\section{Acknowledgments}

This research is supported by the Program for New Century Excellent Talents in University (NCET-13-0037), Natural Science Foundation of China (nos. 70972007, 71271049), and Beijing Municipal Natural Science Foundation (no. 9102015).

\section{References}

[1] Z. Fan and B. Feng, "A multiple attributes decision making method using individual and collaborative attribute data in a fuzzy environment," Information Sciences, vol. 179, no. 20, pp. 3603-3618, 2009.

[2] M. Casanovas and J. M. Merigó, "Fuzzy aggregation operators in decision making with DempsterShafer belief structure," Expert Systems with Applications, vol. 39, pp. 7138-7149, 2012.

[3] T. Chou, S. T. Chou, and G. Tzeng, "Evaluating IT/IS investments: a fuzzy multi-criteria decision model approach," European Journal of Operational Research, vol. 173, no. 3, pp. 10261046, 2006.

[4] P. Hildebrandt and T. Knoke, "Investment decisions under uncertainty - a methodological review on forest science studies," Forest Policy and Economics, vol. 13, no. 1, pp. 1-15, 2011.

[5] H. H. Chen and H. Gu, "A fuzzy ANP model integrated with benefits, opportunities, costs, and risks to prioritize intelligent power grid systems," Mathematical Problems in Engineering, vol. 2013, Article ID 781370, 9 pages, 2013.

[6] B. D. Rouyendegh and S. Erol, "Selecting the best project using the fuzzy ELECTRE method," Mathematical Problems in Engineering, vol. 2012, Article ID 790142, 13 pages, 2012.

[7] L. A. Zadeh, "Fuzzy sets," Information Control, vol. 8, pp. 338353, 1965.

[8] K. T. Atanassov, "Intuitionistic fuzzy sets," Fuzzy Sets and Systems, vol. 20, no. 1, pp. 87-96, 1986.

[9] K. T. Atanassov, Intuitionistic Fuzzy Sets: Theory and Applications, vol. 35, Physica, Heidelberg, Germany, 1999.

[10] R. Chen, "A problem-solving approach to product design using decision tree induction based on intuitionistic fuzzy," European 
Journal of Operational Research, vol. 196, no. 1, pp. 266-272, 2009.

[11] F. Wang, S. Z. Zeng, and C. H. Zhang, "A method based on intuitionistic fuzzy dependent aggregation operators for supplier selection," Mathematical Problems in Engineering, vol. 2013, Article ID 481202, 9 pages, 2013.

[12] Z. Zhang, M. Wang, Y. Hu, J. Yang, Y. Ye, and Y. Li, "A dynamic interval-valued intuitionistic fuzzy sets applied to pattern recognition," Mathematical Problems in Engineering, vol. 2013, Article ID 408012, 16 pages, 2013.

[13] D. F. Li, "Some measures of dissimilarity in intuitionistic fuzzy structures," Journal of Computer and System Sciences, vol. 68, no. 1, pp. 115-122, 2004.

[14] D. Li, "Multiattribute decision making models and methods using intuitionistic fuzzy sets," Journal of Computer and System Sciences, vol. 70, no. 1, pp. 73-85, 2005.

[15] Z. Xu, "Some similarity measures of intuitionistic fuzzy sets and their applications to multiple attribute decision making," Fuzzy Optimization and Decision Making, vol. 6, no. 2, pp. 109-121, 2007.

[16] Z. Xu, "Intuitionistic fuzzy hierarchical clustering algorithms," Journal of Systems Engineering and Electronics, vol. 20, no. 1, pp. 90-97, 2009.

[17] M. M. Xia, Z. S. Xu, and B. Zhu, "Some issues on intuitionistic fuzzy aggregation operators based on Archimedean t-conorm and t-norm," Knowledge-Based Systems, vol. 31, pp. 78-88, 2012.

[18] M. Li, "Extension of axiomatic design principles for multicriteria decision making problems in intuitionistic fuzzy environment," Mathematical Problems in Engineering, vol. 2013, Article ID 813471, 10 pages, 2013.

[19] J. Guo, "Hybrid multicriteria group decision making method for information system project selection based on intuitionistic fuzzy theory," Mathematical Problems in Engineering, vol. 2013, Article ID 859537, 12 pages, 2013.

[20] Y. J. Zhang, P. H. Li, Y. Z. Wang, P. J. Ma, and X. H. Su, "Multiattribute decision making based on entropy under interval-valued intuitionistic fuzzy environment," Mathematical Problems in Engineering, vol. 2013, Article ID 526871, 8 pages, 2013.

[21] L. A. Zadeh, "The concept of a linguistic variable and its application to approximate reasoning," Information Sciences, vol. 8, pp. 199-249, 1975.

[22] F. Herrera and L. Martínez, "A 2-tuple fuzzy linguistic representation model for computing with words," IEEE Transactions on Fuzzy Systems, vol. 8, pp. 746-752, 2000.

[23] J. Lin, J. B. Lan, and Y. H. Lin, "Multi-attribute group decisionmaking method based on the aggregation operators of interval 2-tuple linguistic information," Journal of Jilin Normal University, vol. 1, pp. 5-9, 2009.

[24] Z. S. Xu, "Uncertain linguistic aggregation operators based approach to multiple attribute group decision making under uncertain linguistic environment," Information Sciences, vol. 168, no. 1-4, pp. 171-184, 2004.

[25] Z. S. Xu, "An approach based on similarity measure to multiple attribute decision making with trapezoid fuzzy linguistic variables," Fuzzy Systems and Knowledge Discovery, vol. 3613, pp. 110-117, 2005.

[26] Y. B. Ju, X. Y. Liu, and S. H. Yang, “Trapezoid fuzzy2-tuple linguistic aggregation operators and their application to multiple attribute decision making," Journal of Intelligent \& Fuzzy Systems, 2014.
[27] J. Q. Wang and J. J. Li, “The multi-criteria group decision making method based on multi-granularity intuitionistic two semantics," Science \& Technology Information, vol. 33, pp. 8-9, 2009.

[28] V. Torra and Y. Narukawa, "On hesitant fuzzy sets and decision," in Proceedings of the IEEE International Conference on Fuzzy Systems, pp. 1378-1382, August 2009.

[29] V. Torra, "Hesitant fuzzy sets," International Journal of Intelligent Systems, vol. 25, no. 6, pp. 529-539, 2010.

[30] N. Chen, Z. S. Xu, and M. M. Xia, "Interval-valued hesitant preference relations and their applications to group decision making," Knowledge-Based Systems, vol. 37, pp. 528-540, 2013.

[31] G. Wei, X. Zhao, and R. Lin, "Some hesitant interval-valued fuzzy aggregation operators and their applications to multiple attribute decision making," Knowledge-Based Systems, vol. 46, pp. 43-53, 2013.

[32] X. F. Zhao, R. Lin, and G. W. Wei, "Hesitant triangular fuzzy information aggregation based on Einstein operations and their application to multiple attribute decision making," Expert Systems with Applications, vol. 41, no. 4, pp. 1086-1094, 2014.

[33] L. Wang, M. F. Ni, Z. K. Yu, and L. Zhu, "Power geometric operators of hesitant multiplicative fuzzy numbers and their application to multiple attribute group decision making," Mathematical Problems in Engineering, vol. 2014, Article ID 186502, 16 pages, 2014.

[34] R. M. Rodriguez, L. Martinez, and F. Herrera, "Hesitant fuzzy linguistic term sets for decision making," IEEE Transactions on Fuzzy Systems, vol. 20, no. 1, pp. 109-119, 2012.

[35] Z. M. Zhang and C. Wu, "Hesitant fuzzy linguistic aggregation operators and their applications to multiple attribute group decision making," Journal of Intelligent \& Fuzzy Systems, vol. 26, pp. 2185-2202, 2014.

[36] R. Lin, X. F. Zhao, and G. X. Wei, "Models for selecting an ERP system with hesitant fuzzy linguistic information," Journal of Intelligent Fuzzy Systems, vol. 26, pp. 2155-2165, 2014.

[37] X. Y. Liu, Y. B. Ju, and S. H. Yang, "Hesitant intuitionistic fuzzy linguistic aggregation operators and their applications to multiple attribute decision making," Journal of Intelligent and Fuzzy Systems, 2014.

[38] F. Herrera, E. Herrera-Viedma, and J. L. Verdegay, "A model of consensus in group decision making under linguistic assessments," Fuzzy Sets and Systems, vol. 78, no. 1, pp. 73-87, 1996.

[39] F. Herrera and E. Herrera-Viedma, "Linguistic decision analysis: steps for solving decision problems under linguistic information," Fuzzy Sets and Systems, vol. 115, no. 1, pp. 67-82, 2000.

[40] P. D. Liu, "Some generalized dependent aggregation operators with intuitionistic linguistic numbers and their application to group decision making," Journal of Computer and System Sciences, vol. 79, pp. 131-143, 2013.

[41] M. M. Xia and Z. S. Xu, "Hesitant fuzzy information aggregation in decision making," International Journal of Approximate Reasoning, vol. 52, no. 3, pp. 395-407, 2011.

[42] Z. Xu, "On consistency of the weighted geometric mean complex judgement matrix in AHP," European Journal of Operational Research, vol. 126, no. 3, pp. 683-687, 2000. 


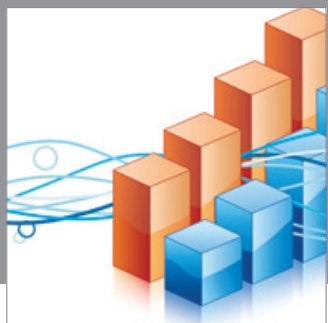

Advances in

Operations Research

mansans

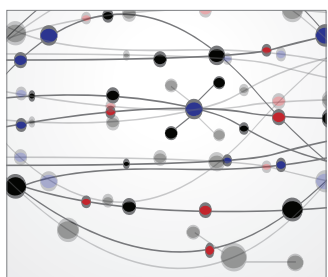

The Scientific World Journal
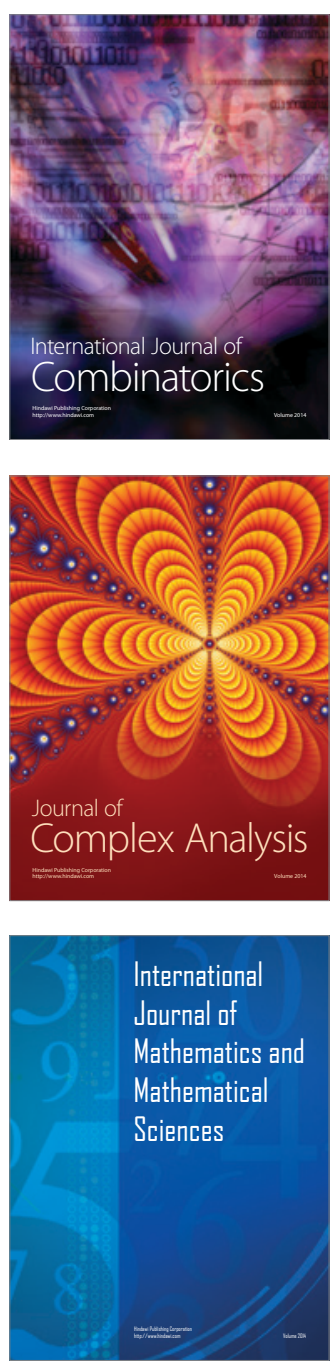
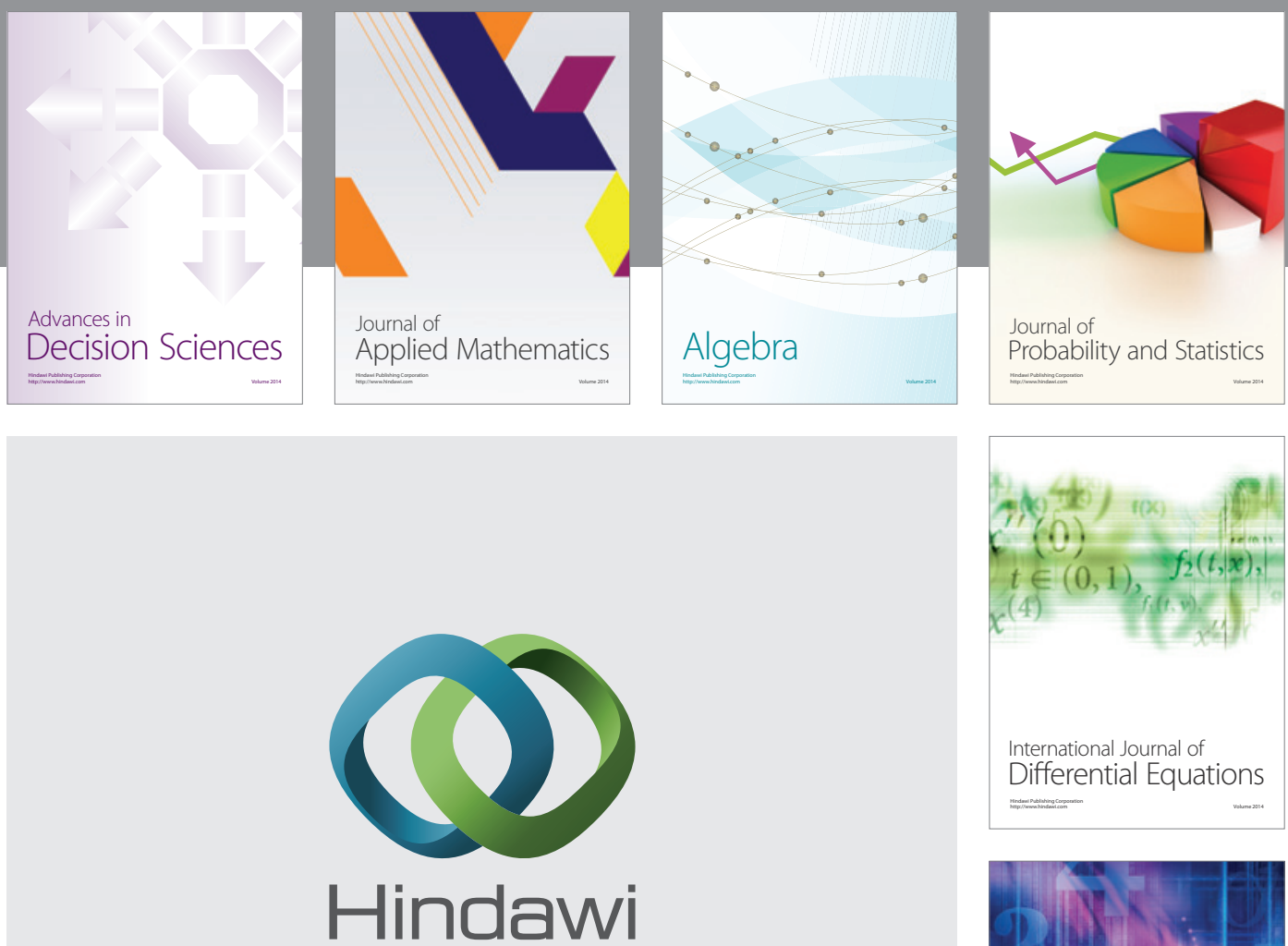

Submit your manuscripts at http://www.hindawi.com
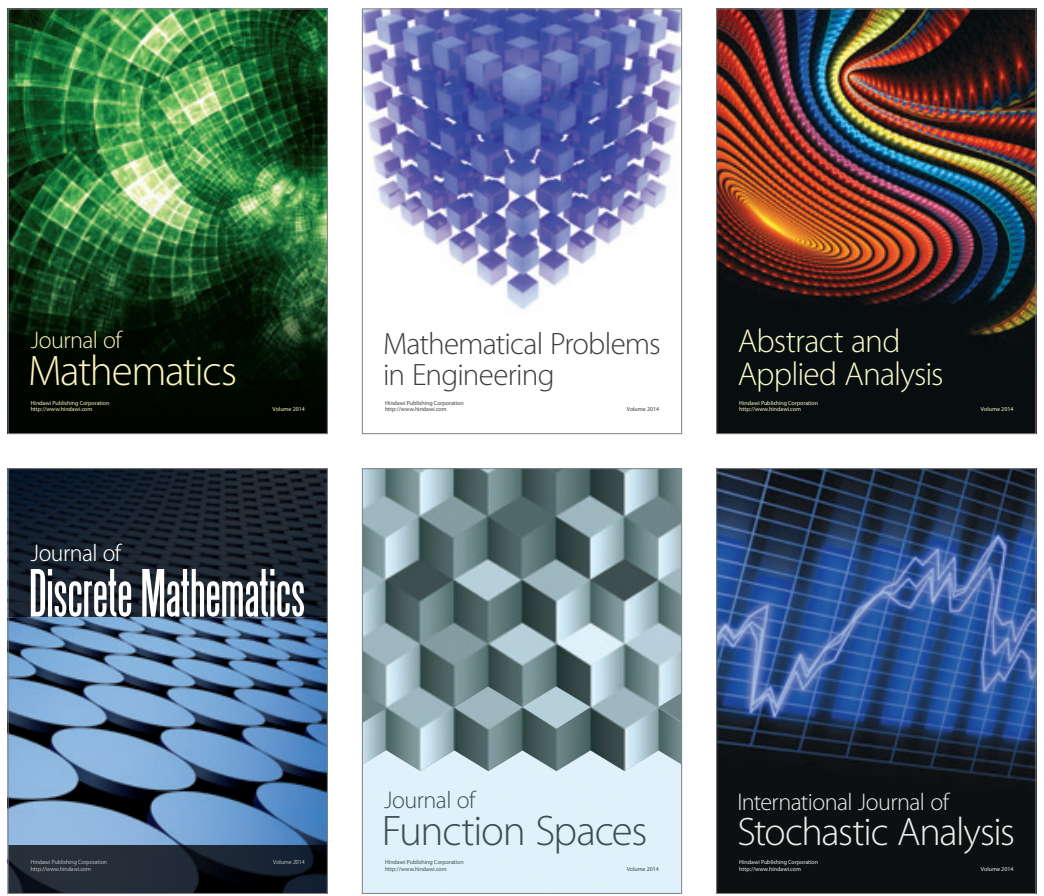

Journal of

Function Spaces

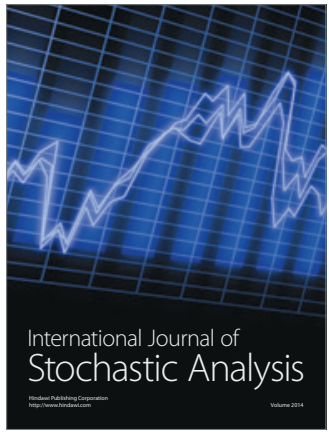

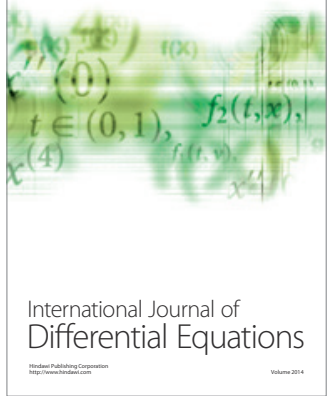
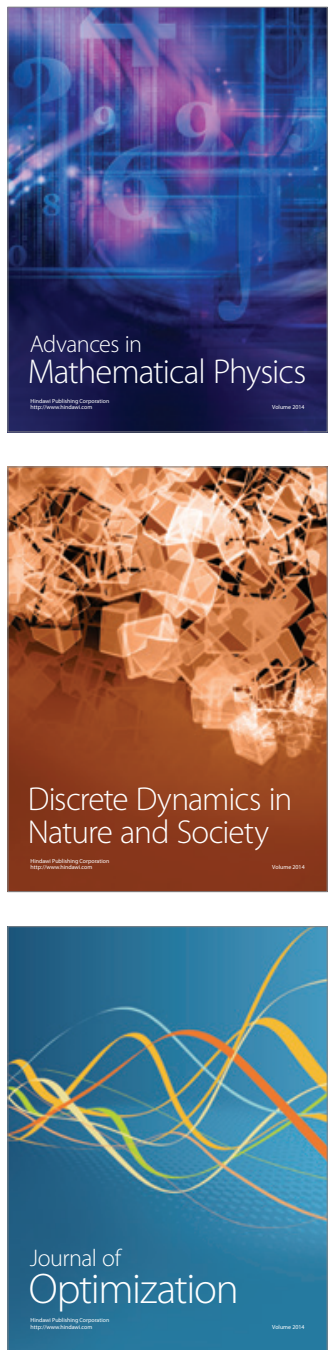